\title{
The Optimisation of Potent ATAD2 and CECR2
}

\section{Bromodomain Inhibitors with an Atypical}

\section{Binding Mode.}

Simon C. C. Lucas,,,$+ ;$ Stephen J. Atkinson, ${ }^{*}{ }^{\ddagger}$ Paul Bamborough, ${ }^{\S}$ Heather Barnett, ${ }^{\ddagger}$ Chun-wa Chung, ${ }^{\S}$ Laurie Gordon, ${ }^{\lfloor}$Darren J. Mitchell, ${ }^{\ddagger}$ Alexander Phillipou,, Rab K. Prinjha, ${ }^{\ddagger}$ Robert J. Sheppard, ${ }^{\ddagger} ¥$ Nicholas C. O. Tomkinson, ${ }^{\dagger}$ Robert J. Watson,,${ }^{\ddagger}$ and Emmanuel H. Demont. ${ }^{\ddagger}$

${ }^{\dagger}$ Epigenetics Discovery Performance Unit, ${ }^{\S}$ Computational \& Structural Chemistry, Molecular Discovery Research and Biological Sciences GlaxoSmithKline Medicines Research Centre, Gunnels Wood Road, Stevenage, SG1 2NY, United Kingdom.

WestCHEM, Department of Pure and Applied Chemistry, Thomas Graham Building, University of Strathclyde, 295 Cathedral Street, Glasgow, G1 1XL, United Kingdom.

\begin{abstract}
Most bromodomain inhibitors mimic the interactions of the natural acetylated lysine (KAc) histone substrate through key interactions with conserved asparagine and tyrosine residues within the binding pocket. Herein we report the optimisation of a series of phenyl sulfonamides which exhibit a novel mode of binding to non-Bromodomain and Extra Terminal Domain (non-BET) bromodomains through displacement of a normally conserved network of four water molecules. Starting from an initial hit molecule we report its divergent optimisation towards the ATPase
\end{abstract}


family AAA domain containing 2 (ATAD2) and Cats Eye Syndrome Chromosome Region, Candidate 2 (CECR2) domains. This work concludes with the identification of (R)-55 (GSK232), a highly selective, cellularly penetrant CECR2 inhibitor with excellent physicochemical properties.

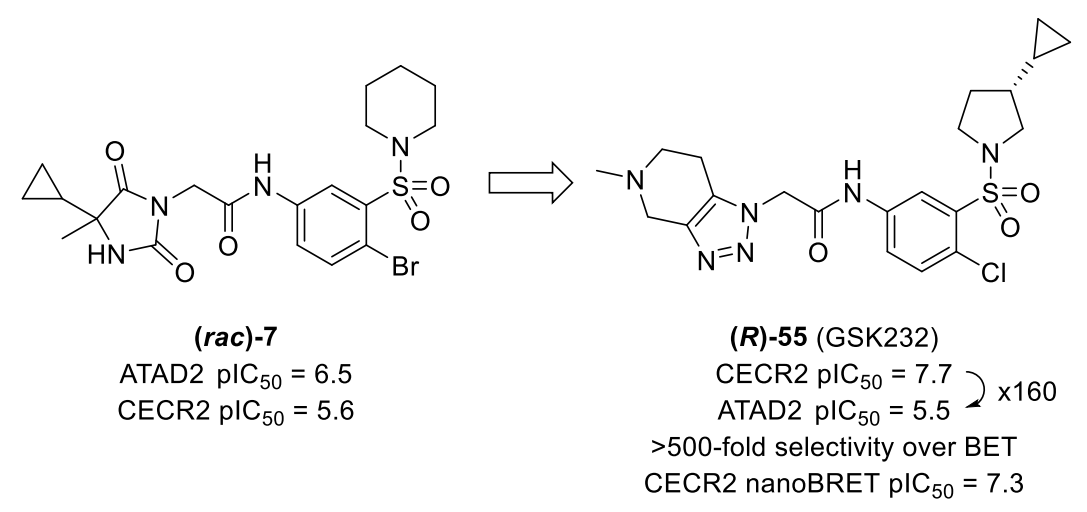

\section{INTRODUCTION}

The Bromodomain and Extra-Terminal Domain (BET) family of bromodomain containing proteins is a well-established therapeutic target for small molecule inhibition, leading to efficacy in both oncology and immuno-inflammation indications. ${ }^{1-3}$ It has been shown that BET proteins organise on superenhancer and enhancer regions and profoundly regulate gene expression relevant to a range of diseases. ${ }^{4-5}$ Indeed, many small molecule BET bromodomain inhibitors, which block the interaction of BET with histones and chromatin, are currently progressing through clinical trials. ${ }^{6}$ However, the BET family represent just 8 of the 61 known human bromodomains, therefore, it is logical to propose that other bromodomains may control the expression of genes crucial to other diseases. ${ }^{7-9}$ Despite this promising hypothesis, the pharmacological relevance of inhibiting these bromodomains using small molecules is still largely unknown. Therefore, before investment in a full drug discovery programme, these targets need to be fully validated. ${ }^{8-13}$ Work in our group has recently been focused on developing tool molecules for the ATPase family AAA 
domain containing 2 (ATAD2) and Cats Eye Syndrome Chromosome region, candidate 2 (CECR2) bromodomains, with a particular focus on novel chemotypes. ${ }^{14-16}$

ATAD2 is a promising oncogene which is overexpressed in multiple, unrelated human cancers. ${ }^{17-18}$ Protein knockdown experiments have linked ATAD2 to cell survival, proliferation and migration pathways. ${ }^{19}$ CECR2 is a bromodomain containing transcription factor which is involved in neurulation through the chromatin remodeling complex SNF2L. ${ }^{20}$ It has also been implicated in oncology using a functional genomics approach and is involved in the formation of $\gamma-\mathrm{H} 2 \mathrm{AX}$ foci in response to DNA double strand breaks. ${ }^{21-22}$

The ATAD2 and CECR2 bromodomains are exciting targets for drug discovery and, consequently, inhibitors for both bromodomains are starting to appear in the literature. Computational modelling had previously predicted the ATAD2 bromodomain to be amongst the least tractable of the bromodomain family, however, work by our group amongst others has shown that the optimisation of sub-micromolar inhibitors is possible. ${ }^{23-25}$ The first small molecule inhibitor (Fig. 1) published by our group was naphthyridone $1 .^{26}$ Despite showing relatively modest activity compared to the leading BET inhibitors (ATAD2 pIC $_{50}=5.9$ ) this was a significant step forward against what was predicted to be one of the least tractable bromodomains. ${ }^{23}$ Naphthyridone 1 was optimized to afford 2 (GSK8814), a cell-permeable and selective tool molecule. ${ }^{27-28}$ Recently, an isoform selective ATAD2 inhibitor, 3 (BAY-850) was published. ${ }^{29}$ This showed excellent ATAD2 potency and no measurable inhibition of other bromodomains. The compound displayed a unique binding mode whereby it bound to a dimer of ATAD2 as determined by mass spectrometry.

There are currently three reported small molecule inhibitors of CECR2 (Fig. 1). The first, 4 (NVS-CECR2-1) is a highly selective tool molecule. ${ }^{30}$ It has nanomolar activity in an isothermal 
calorimetry (ITC) assay $\left(\mathrm{pK}_{\mathrm{d}}=7.1\right)$ and displays robust activity in cellular fluorescence recovery after photobleaching (FRAP) and nano bioluminescence resonance energy tranfer (nanoBRET) assays. However, the authors describe the compound as being poorly soluble. The poor solubility of this chemotype was addressed through a collaborative effort between the SGC and Takeda which delivered 5 (TP-238) as a dual CECR2/bromodomain PHD finger transcription factor (BTPF) tool compound. ${ }^{31}$ The other available chemical probe is $\mathbf{6}$ (GNE-886), which has a CECR2 TR-FRET pIC $_{50}$ of 7.8 equating to a 100 -fold selectivity window over the closest bromodomains. ${ }^{32}$ The authors demonstrated cellular permeability and target engagement, identifying it as a suitable tool molecule.
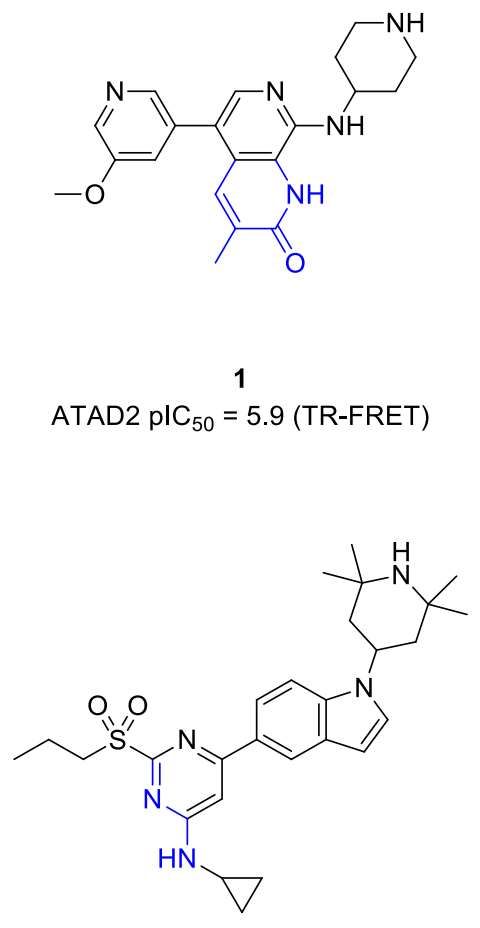

NVS-CECR2-1, 4 CECR2 $\mathrm{pK}_{\mathrm{d}}=7.1$ (ITC)

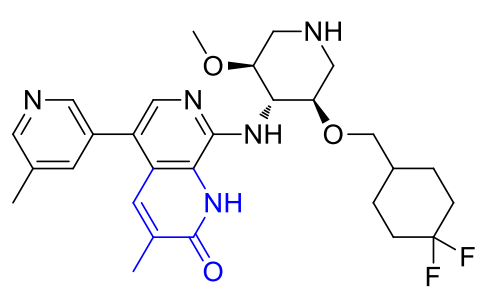

GSK8814, 2 ATAD2 $\mathrm{pK}_{\mathrm{d}}=8.1$ (ITC)

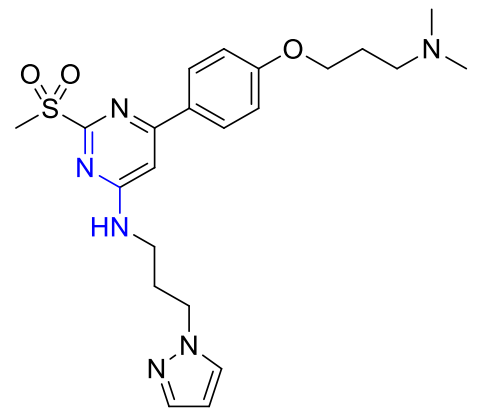

TP-238, 5 CECR2 $\mathrm{pK}_{\mathrm{d}}=8.0$ (ITC)
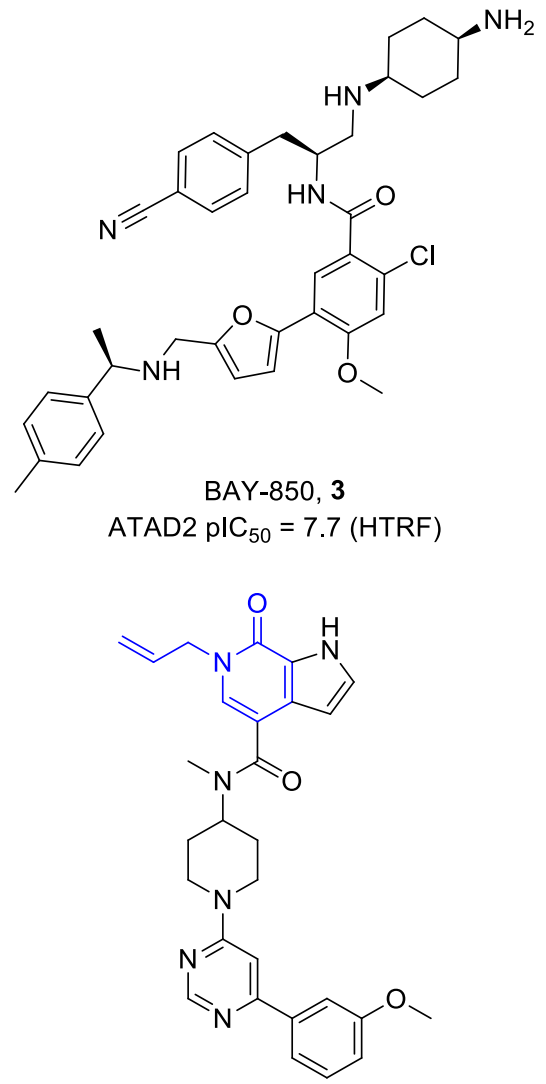

GNE-886, 6 CECR2 plC $_{50}=7.8$ (TR-FRET)

Fig. 1. Small molecule inhibitors of ATAD2 and CECR2 with KAc mimetics shown in blue. 
Whilst tool molecules have been identified for these bromodomains, fully validating any results observed with these tools will rely on the availability of additional molecules which have differentiated chemotypes. ${ }^{13-14}$ We recently disclosed the output of a high throughput screen (HTS) which identified a series of phenyl sulfonamides as ATAD2 inhibitors. ${ }^{33}$ Phenyl sulfonamide (rac)-7 was identified as a suitable starting point for optimisation into a chemical tool for both ATAD2 and CECR2 (Table 1$)$. It showed activity against ATAD2 $\left(\mathrm{pIC}_{50}=6.3\right)$ and CECR2 $\left(\mathrm{pIC} \mathrm{C}_{50}\right.$ = 5.6) using TR-FRET assays. As in our earlier work on the naphthyridone series, we moved from a peptide, to a ligand displacement TR-FRET assay due to improved assay robustness. ${ }^{27}$ Since the data was concordant (e.g. (rac)-7: 6.5 vs. 6.3), the ligand displacement assay will be used herein. Importantly, (rac)-7 showed little affinity for either bromodomain of BRD4 ( $\left.\mathrm{pIC}_{50} \leq 4.7\right)$, used in this work as a representitive example of the BET family due to the high sequence homology between family members (for full BET data on (rac)-7, $(\boldsymbol{S}, \boldsymbol{S})-\mathbf{3 2}$, and (R)-55 see Supporting Information). High BET selectivity (>100-fold) is desirable due to the strong phenotype observed with BET inhibitors. Phenyl sulfonamide (rac)-7 was in a good physicochemical space as defined by ChromLogD (a chromatographic measure of lipophilicity measured at 4.8), the Property Forecast Index (PFI (ChromLogD + \#Ar), 5.8) and clogP (2.8). ${ }^{34-36}$ The series had high kinetic solubility as measured by chemiluminescence nitrogen detection (CLND) solubility (93 $\mu \mathrm{g} \mathrm{mL} \mathrm{m}^{-1}$ ) and good permeability through an artificial lipid membrane $\left(200 \mathrm{~nm} \mathrm{~s}^{-1}\right) \cdot{ }^{37-39}$ Charged aerosol detection (CAD) solubility was also used in this work and an internal analysis has shown that this is equivalent to CLND (see Supporting Information). ${ }^{40}$ 
Table 1. Hit phenyl sulfonamide identified from a HTS against ATAD2.

\begin{tabular}{|c|c|}
\hline \multicolumn{2}{|l|}{$($ rac $)-7$} \\
\hline ATAD2 (peptide) pIC $\mathrm{pl}_{50}(\mathrm{n})$ & $6.5(8)$ \\
\hline ATAD2 (ligand) pIC $50(\mathrm{n})$ & $6.3(5)$ \\
\hline $\mathrm{LE} / \mathrm{LLE}_{\mathrm{at}}$ & $0.25 / 0.26$ \\
\hline CECR2 pIC 50 (n) / Sel. & $5.6(2) / 5 x$ \\
\hline BRD4 BD1 pIC $50(\mathrm{n}) /$ Sel. & $4.3(1)^{\mathrm{a}} / 100 \mathrm{x}$ \\
\hline BRD4 BD2 pIC50 (n) / Sel. & $4.7(3) / 40 \mathrm{x}$ \\
\hline ChromLogD / PFI / clogP & $4.8 / 5.8 / 2.8$ \\
\hline $\operatorname{CLND}\left(\mu \mathrm{g} \mathrm{mL} \mathrm{L}^{-1}\right)$ & 93 \\
\hline $\operatorname{AMP}\left(\mathrm{nm} \mathrm{s}^{-1}\right)$ & 200 \\
\hline
\end{tabular}

${ }^{a}$ Data is $<4.3$ on $2 / 3$ test occasions.

The phenyl sulfonamides, such as (rac)-8 bound to the bromodomain of ATAD2 in a noncanonical fashion, completely displacing the normally conserved water network from the base of the binding pocket (Fig 2. A). One of the sulfonamide oxygens replaces the interactions of W1 and makes a H-bond to Y1021. Additionally, the characteristic $110.5^{\circ}$ angle of the sulfonamide, positions the piperidine into a lipophilic pocket formed by the BC loop. An ortho substituent on the aromatic ring overlays with W2. Initial SAR studies revealed that a halide substituent on the 
aromatic ring was optimal for potency. A bromide was typically 5 -fold more potent than a chloride. Truncation of the hydantoin back to an ethylamide showed a 50-fold drop in potency (data not shown) suggesting a significant binding contribution from this moiety. ${ }^{33}$ This can be rationalised by the two binding interactions of the hydantoin carbonyl groups with R1007 and the backbone NH of D1014 (Fig 2. B). However, it should be noted that multiple R1007 conformations were observed in different structures, indicating a degree of flexibility for this residue. Furthermore, the hydantoin $N H$ did not appear to pick up any specific interactions with the protein.

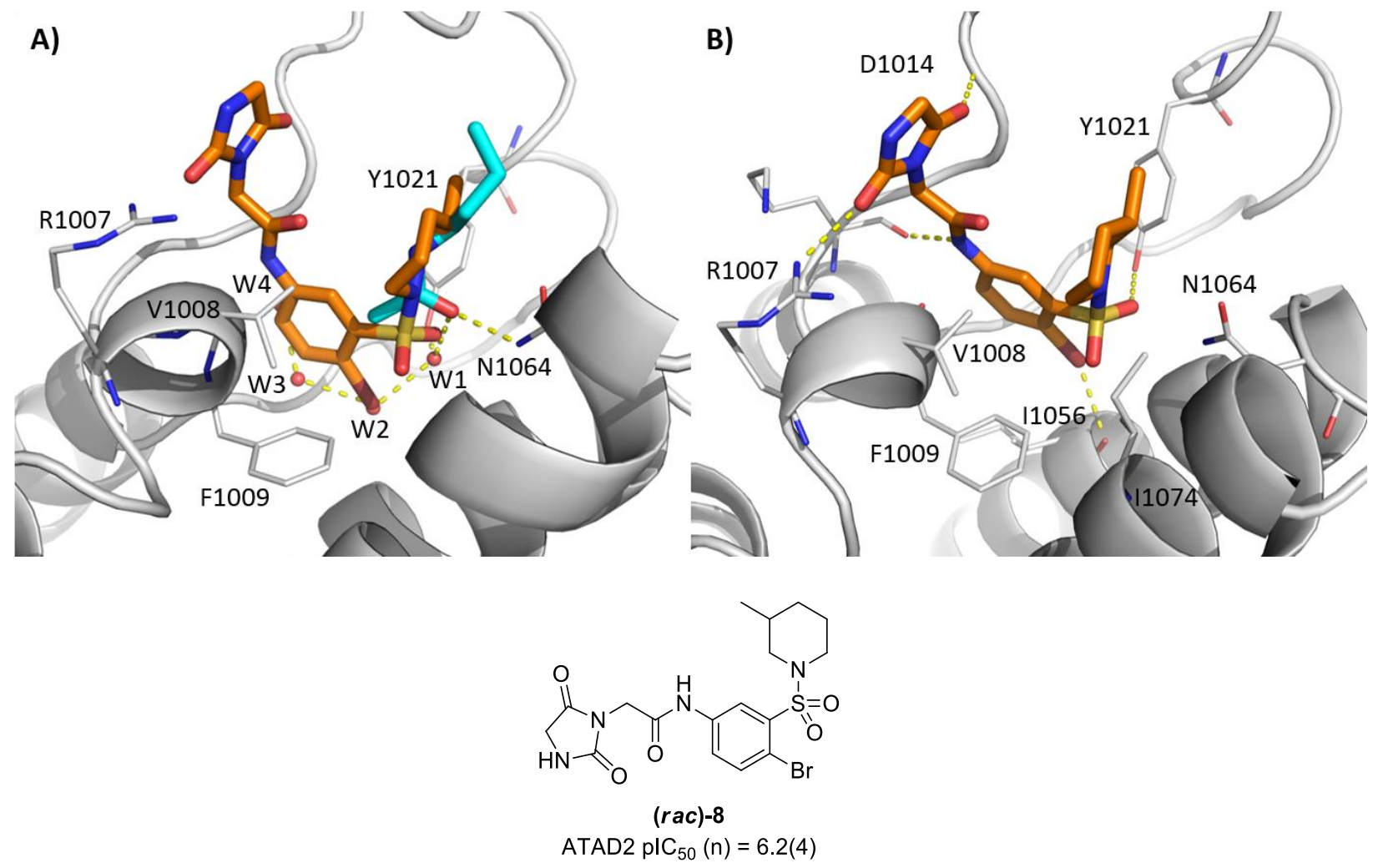

Fig. 2. A) X-ray crystal structure of (rac)-8 (pdb6S55) overlaid with KAc binding in ATAD2 (pdb4QSP). The density fitted the $S$-enantiomer better and so this was modelled. The conserved network of waters (W1-4) shown in the base of the binding pocket are displaced by the phenyl sulfonamide ligand. B) Key contacts between the ligand ((rac)-8) and ATAD2 are shown as 
yellow dashes, A halogen bond between the aryl bromide and the backbone carbonyl group of I1056 is present at the base of the KAc recognition site. One of the sulfonamide oxygens makes a H-bond to Y1021 and the two carbonyl groups of the hydantoin make H-bonds to R1007 and D1014.

The potency of (rac)-7 against ATAD2 and its selectivity over the BET family (>40-fold), combined with the good physicochemical properties of this molecule and the novel binding mode of the phenyl sulfonamides, made it an attractive starting point for our investigation. Additionally, potency for CECR2 presented the opportunity for divergent optimisation. Within this manuscript we report the optimisation of (rac)-7 into potent inhibitors of ATAD2 and CECR2 respectively.

\section{RESULTS AND DISCUSSION}

\section{Optimisation towards an ATAD2 inhibitor:}

As previously disclosed during the discovery of this template, preliminary SAR generation efforts had focused on the aryl substituent and the hydantoin vector. The binding contribution of the sulfonamide substituent was not evaluated at this stage. ${ }^{33}$ As a starting point for SAR expansion towards ATAD2 potency and selectivity, piperidine 10 was either truncated or expanded to the 5and 7-membered analogues (9 and 11 respectively, Table 2). For synthetic feasibility, these were prepared with a chloro-aryl substituent and an unfunctionalised hydantoin. Pyrrolidine 9 was the most potent $\left(\mathrm{pIC}_{50}=6.0\right)$ and ligand efficient of the three heterocycles against ATAD2, which was attributed to a good shape complementarity of the substituent with the lipophilic pocket (formed by the BC loop) of the protein. Truncation of the heterocycle to dimethyl sulfonamide $\mathbf{1 2}$ led to a significant decrease in potency $\left(\mathrm{pIC}_{50}=4.9\right)$ against $\mathrm{ATAD} 2$, a trend mirrored in $\mathrm{CECR} 2\left(\mathrm{pIC} \mathrm{C}_{50}=\right.$ 
4.2). As the pyrrolidine was the optimal size, functionalisation of the ring was then investigated. A methyl substituent at the 3-position of the pyrrolidine (13) was tolerated but no increase in ATAD2 potency or selectivity over CECR2 was observed for either enantiomer. Whilst both enantiomers of the 3-methyl substituent were well tolerated, gem-dimethyl $\mathbf{1 4}$ showed a $0.5 \log$ unit decrease in potency, suggesting the steric demands of this analogue are not accommodated by the binding pocket. Interestingly, cyclopropyl 15 was comparable with the des- and mono- methyl analogues (9 and (S)-13), however, it had a slightly lower ligand efficiency. Bis-substitution at the 3-and 4- position was then investigated. The trans-configuration ((rac)-16) gave a $0.5 \log$ unit increase in potency compared to $(\boldsymbol{S})$-13. This included a slight increase in LE but a small decrease in $\mathrm{LLE}_{\text {at. }}$ Conversely, the cis-configuration $\mathbf{1 7}$ was poorly tolerated and less potent $\left(\mathrm{pIC}_{50}=5.7\right)$ than the monomethyl examples. Extending the 3-position substituent to ethyl (rac)-18 or ether $(r a c)-19$, was tolerated, but neither offered any improvements in terms of potency or ligand efficiency compared to 9 and $(\boldsymbol{S})-\mathbf{1 3}$. Cyclopropyl ( $\mathbf{r a c}$ )-20 was notable for its increased CECR2 potency $v s .(S)-13$, and was now equipotent against the two proteins. Substitution at the 2-position to afford pyrrolidine $(\boldsymbol{R})$-21 was less well tolerated, with a drop in $\mathrm{pIC}_{50}$ to 5.6. The more substantive change of a sulfonamide to a cyclohexyl sulfone $\left(\mathbf{2 2}\right.$, entry $\left.7, \mathrm{pIC}_{50}<4.0\right)$ was not tolerated in accordance with the predicted importance of the directionality confered by the sulfonamide (vide supra). Likewise, sulfonyl-imidazole $\mathbf{2 3}$ (entry 8) was inactive against ATAD2 and CECR2 at the concentrations tested. All of the examples tested showed no appreciable affinity for BRD4 BD1, maintained a moderate bias for ATAD2 over CECR2, and showed desirable levels of solubility $\left(\geq 116 \mu \mathrm{g} \mathrm{mL} \mathrm{m}^{-1}\right)$. Whilst no increases in ATAD2 selectivity were observed, pyrrolidines $9,(S)-13$ and $(\mathbf{r a c})$-16 were identified as the optimal sulfonamides due to their potency and ligand efficiency. 
Table 2. Exploration of the sulfonamide vector.<smiles>[R]S(=O)(=O)c1cc(NC(=O)CN2C(=O)CNC2=O)ccc1Cl</smiles>

\begin{tabular}{|c|c|c|c|c|c|c|c|}
\hline & $\mathbf{R}$ & $\begin{array}{l}\text { ATAD2 } \\
\text { pIC50 (n) }\end{array}$ & $\begin{array}{c}\text { ATAD2 } \\
\text { LE / } \\
\text { LLE }_{a t}\end{array}$ & $\begin{array}{c}\text { CECR2 } \\
\text { pIC50 (n) } \\
\text { / Sel. }\end{array}$ & \begin{tabular}{|c|} 
BRD4 \\
BD1 \\
pIC50 (n)
\end{tabular} & $\begin{array}{l}\text { Chrom } \\
\text { LogD }\end{array}$ & $\begin{array}{c}\text { CLND } \\
\text { sol. } \\
\left(\mu \mathrm{g} \mathrm{mL}^{-1}\right)\end{array}$ \\
\hline 9 & & $6.0(4)$ & $\begin{array}{l}0.32 / \\
0.38\end{array}$ & $\begin{array}{c}5.4(4) / \\
4 x\end{array}$ & $<4.3(4)$ & 2.6 & $\geq 259$ \\
\hline 10 & & $5.6(6)$ & $\begin{array}{c}0.28 / \\
0.32\end{array}$ & $\begin{array}{c}4.5(4) / \\
13 x\end{array}$ & $<4.3(2)$ & 3.5 & $\geq 176$ \\
\hline 11 & & $5.9(6)$ & $\begin{array}{c}0.29 / \\
0.30\end{array}$ & $\begin{array}{c}4.9(4) / \\
10 x\end{array}$ & $<4.3(4)$ & 3.7 & $\geq 174$ \\
\hline 12 & & $4.9(6)$ & $\begin{array}{c}0.28 / \\
0.37\end{array}$ & $\begin{array}{c}4.1(4)^{\mathrm{a}} / \\
6 \mathrm{x}\end{array}$ & $4.4(2)$ & 2.2 & $\geq 129$ \\
\hline$(S)-13$ & & $6.1(8)$ & $\begin{array}{l}0.31 / \\
0.35\end{array}$ & $\begin{array}{c}5.5(8) / \\
4 x\end{array}$ & $<4.3(2)$ & 3.2 & $\geq 153$ \\
\hline$(R)-13$ & & $6.0(6)$ & $\begin{array}{l}0.30 / \\
0.34\end{array}$ & $\begin{array}{c}5.3(2) / \\
5 x\end{array}$ & $<4.3(4)$ & 3.2 & 175 \\
\hline 14 & - & $5.5(6)$ & $\begin{array}{l}0.27 / \\
0.28\end{array}$ & $\begin{array}{c}4.6(3) / \\
8 x\end{array}$ & $<4.3(2)$ & 3.8 & $\geq 153^{\mathrm{c}}$ \\
\hline
\end{tabular}




\begin{tabular}{|c|c|c|c|c|c|c|c|}
\hline 15 & & $6.0(8)$ & $\begin{array}{l}0.29 / \\
0.34\end{array}$ & $\begin{array}{c}5.4(4) / \\
4 \mathrm{x}\end{array}$ & $<4.3(2)$ & 3.3 & $\geq 158$ \\
\hline $\begin{array}{c}\text { (rac)- } \\
16\end{array}$ & & $6.6(6)$ & $\begin{array}{l}0.32 / \\
0.34\end{array}$ & $\begin{array}{c}5.7(2) / \\
8 x\end{array}$ & $4.7(1)^{\mathrm{b}}$ & 3.8 & 167 \\
\hline 17 & & $5.7(6)$ & $\begin{array}{l}0.28 / \\
0.29\end{array}$ & $\begin{array}{c}4.7(2) / \\
10 \mathrm{x}\end{array}$ & $<4.3(2)$ & 3.7 & 156 \\
\hline $\begin{array}{c}\text { (rac)- } \\
18\end{array}$ & & $6.2(8)$ & $\begin{array}{l}0.30 / \\
0.32\end{array}$ & $\begin{array}{c}5.9(4) / \\
2 \mathrm{x}\end{array}$ & $<4.3(4)$ & 3.8 & $\geq 175$ \\
\hline $\begin{array}{c}\text { (rac)- } \\
19\end{array}$ & & $6.0(4)$ & $\begin{array}{l}0.28 / \\
0.38\end{array}$ & $\begin{array}{c}5.4(2) / \\
4 \mathrm{x}\end{array}$ & $<4.3(2)$ & 2.6 & $\geq 352$ \\
\hline $\begin{array}{c}(r a c)- \\
20\end{array}$ & & $6.3(4)$ & $\begin{array}{l}0.30 / \\
0.32\end{array}$ & $6.3(3) /-$ & $<4.3(2)$ & 4.0 & $\geq 169^{\mathrm{c}}$ \\
\hline$(R)-21$ & & $5.6(6)$ & $\begin{array}{l}0.28 / \\
0.32\end{array}$ & $\begin{array}{c}5.1(4) / \\
3 \mathrm{x}\end{array}$ & $4.5(1)^{b}$ & 3.1 & $\geq 201$ \\
\hline 22 & & $<4.0(2)$ & $\begin{array}{l}0.20 / \\
0.21\end{array}$ & $\begin{array}{c}<4.0(6) / \\
-\end{array}$ & $<4.3(2)$ & 3.6 & 116 \\
\hline 23 & & $<4.0(4)$ & $\begin{array}{l}0.21 / \\
0.29\end{array}$ & $\begin{array}{c}<4.0(6) / \\
-\end{array}$ & $<4.3(2)$ & 2.1 & $\geq 155$ \\
\hline
\end{tabular}

${ }^{\mathrm{a} D a t a}$ is $<4.0$ on $1 / 5$ test occasions; ${ }^{\mathrm{b}} \mathrm{Data}$ is $<4.3$ on $2 / 3$ test occasions; ${ }^{\mathrm{c}} \mathrm{CAD}$ solubility.

Attention then turned to the amide vector, which directed the hydantoin moiety towards R1007 and D1014 (Fig 2). The HTS had identified the hydantoin as an effective substituent but 
it was important to fully explore the SAR of this region to further elicidate the differences in ATAD2 and CECR2 binding (Table 3). ${ }^{33}$ As before, the aryl chloride was used for synthetic feasibility and the more optimal pyrrolidine sulfonamide was employed. As expected, the unsubstituted hydantoin 9 showed good potency $\left(\mathrm{pIC}_{50}=6.0\right)$, though, it was characterised by a low artificial membrane permeability (AMP $<3 \mathrm{~nm} \mathrm{~s}^{-1}$ ). This is most likely due to the low lipophilicity of this molecule. Although AMP does not neccessarily correlate with cell penetration, this was a high throughput metric which helped guide design. The methyl (rac-24) and dimethyl (25) analogues increased permeability further and maintained a similar ATAD2 potency $\left(\mathrm{pIC}_{50}=5.9\right.$ and 5.8 respectively). Here, alpha substitution of the H-bond donor $\mathrm{NH}$ increases lipophilicity by $0.4-0.8 \log$ units allowing it to more easily pass though the hydrophobic portion of membranes. The geminally substituted (rac)-26 further raised the predicted permeability achieving a desirable value of $100 \mathrm{~nm} \mathrm{~s}^{-1}$ and also maintained potency at ATAD2. Interestingly, 2,4-oxazolidinedione $27\left(\mathrm{pIC}_{50}=5.9\right)$ was also well tolerated, supporting the crystallographic observation that the hydantoin $N H$ wasn't making any specific interactions. This was further supported by pyrrolidinedione $\mathbf{2 8}$, which also maintained a similar potency of 5.8 (c.f. hydantoins 9, 24-26). However, further simplification of the hydantoin substituent to 2-pyrrolidinone 29 saw a large decrease in potency $\left(\mathrm{pIC}_{50}=4.3\right)$. This shows, in accord with the crystallography (Fig. 2), that both carbonyl groups are important for binding to ATAD2. In fact, 2-pyrrolidinone $\mathbf{2 9}$ offered little difference in potency compared to truncated acetamide $30\left(\mathrm{pIC}_{50}=4.5\right)$. Pleasingly, 24-30 maintained good solubility $(>94 \mu \mathrm{g}$ $\mathrm{mL}^{-1}$ ), and, none of the compounds tested showed any appreciable affinity for the BET family. Unfortunately, potency for CECR2, largely tracked with ATAD2 and selectivity between the 
two bromodomains was not forthcoming. In summary, hydantoin (rac)-26 offered the highest potency for ATAD2 combined with the best balance of physicochemical properties.

Table 3. Investigation of the Hydantoin substituent.<smiles>[R]CC(=O)Nc1ccc(Cl)c(S(=O)(=O)N2CCCC2)c1</smiles>

\begin{tabular}{|c|c|c|c|c|c|c|c|c|}
\hline & $\mathbf{R}$ & $\begin{array}{l}\text { ATAD2 } \\
\operatorname{pIC}_{50}(n)\end{array}$ & $\begin{array}{c}\text { ATAD2 } \\
\text { LE / } \\
\text { LLE }_{a t}\end{array}$ & $\begin{array}{c}\text { CECR2 } \\
\operatorname{pIC}_{50}(\mathrm{n}) \\
/ \text { Sel. }{ }^{\mathrm{a}}\end{array}$ & $\begin{array}{c}\text { BRD4 } \\
\text { BD1 } \\
\operatorname{pIC}_{50}(n)\end{array}$ & $\begin{array}{c}\text { Chrom } \\
\text { LogD / } \\
\text { PFI }\end{array}$ & $\begin{array}{c}\text { CAD } \\
\text { Sol. } \\
(\mu \mathrm{g} \\
\left.\mathrm{mL}^{-1}\right)\end{array}$ & $\begin{array}{r}\text { AMP } \\
(\mathbf{n m} \\
\left.\mathrm{s}^{-1}\right)\end{array}$ \\
\hline 9 & & $6.0(4)$ & $\begin{array}{l}0.32 / \\
0.38\end{array}$ & $\begin{array}{c}5.4(2) / \\
4 \mathrm{x}\end{array}$ & $<4.3(4)$ & 2.6 & $\geq 343$ & $<3$ \\
\hline $\begin{array}{r}(\text { rac }) \\
-24\end{array}$ & & $5.9(6)$ & $\begin{array}{l}0.30 / \\
0.34\end{array}$ & $\begin{array}{c}5.2(4) / \\
5 \mathrm{x}\end{array}$ & $<4.3(2)$ & 3.0 & $\geq 259^{\mathrm{e}}$ & 12 \\
\hline 25 & & $5.8(4)$ & $\begin{array}{c}0.28 / \\
0.30\end{array}$ & $\begin{array}{c}5.3(4) / \\
3 x\end{array}$ & $<4.3(2)$ & 3.4 & $\geq 158$ & 18 \\
\hline $\begin{array}{l}(r a c) \\
-26\end{array}$ & & $6.0(4)$ & $\begin{array}{l}0.27 / \\
0.28\end{array}$ & $\begin{array}{c}5.8(2) / \\
2 \mathrm{x}\end{array}$ & $<3.3(2)^{\mathrm{c}}$ & 4.2 & $148^{\mathrm{e}}$ & 100 \\
\hline 27 & & $5.9(2)$ & $\begin{array}{l}0.31 / \\
0.37\end{array}$ & $\begin{array}{c}5.8(4) / \\
1 \mathrm{x}\end{array}$ & $<4.3(2)$ & 3.6 & 94 & 54 \\
\hline 28 & & $5.9(6)$ & $\begin{array}{l}0.31 / \\
0.35\end{array}$ & $\begin{array}{c}5.4(4) / \\
3 \mathrm{x}\end{array}$ & $<4.3(2)$ & 3.3 & $\geq 106$ & 42 \\
\hline
\end{tabular}




\begin{tabular}{|c|c|c|c|c|c|c|c|c|}
\hline 29 & 0 & $4.3(6)$ & $\begin{array}{l}0.24 / \\
0.25\end{array}$ & $\begin{array}{l}4.7(2) / \\
3 \times(C)\end{array}$ & $<4.3(2)$ & 3.4 & $181^{\mathrm{e}}$ & 120 \\
\hline 30 & $\mathrm{H}$ & $4.5(4)$ & $\begin{array}{l}0.32 / \\
0.29\end{array}$ & $\begin{array}{c}4.1(4)^{\mathrm{b}} / \\
3 \mathrm{x}\end{array}$ & $3.7(2)^{\mathrm{d}}$ & 3.4 & $\geq 122$ & 270 \\
\hline
\end{tabular}

${ }^{\mathrm{a}}(\mathrm{C})$ denotes selectivity for CECR 2 ; ${ }^{\mathrm{b}}$ Data is $<4.0$ on $2 / 6$ test occasions; ${ }^{\mathrm{c}}$ Data is $<4.3$ on $1 / 3$ test occasions; ${ }^{\mathrm{d}}$ Data is $<4.3$ on $4 / 6$ test occasions; ${ }^{\mathrm{e}} \mathrm{CLND}$ solubility;

If the SAR of the sulfonamide and amide groups were addidive, the combination of the three most potent sulfonamide groups (Table 2), the 3-methyl-3-cyclopropyl hydantoin (Table 3) and bromide should afford optimal ATAD2 inhibitors (Table 4). Unfortunately, (S)-31 did not show the expected increase in potency when the pyrrolidine was combined with the other substituents. However, addition of the 3-methyl substituent increased potency by $0.3-0.5 \log$ units leading to a $\mathrm{pIC}_{50}$ of 7.2 for the most potent diastereomer $((\boldsymbol{S}, \boldsymbol{S})$-32). Phenyl sulfonamide $(\boldsymbol{S}, \boldsymbol{S})-\mathbf{3 2}$ maintained the excellent solubility and physico-chemical profile of the starting hit and had a 5fold bias for ATAD2 over CECR2. This profile was a marginal improvement over the hydantoin epimer $(\boldsymbol{R}, \boldsymbol{S})$-32, and consequently, $(\boldsymbol{S}, \boldsymbol{S})$-32 was nominated for further profiling. In agreement with previous SAR, trans 3,4-dimethyl pyrrolidine 33 increased affinity for ATAD2 ( $\left.\mathrm{pIC}_{50}=7.6\right)$. However, $\mathbf{3 3}$ was less soluble $\left(49 \mu \mathrm{g} \mathrm{mL}^{-1}\right)$, potentially driven by the increased lipophilicity of this analogue.

Table 4. Combination of hydantoin substituent and sulfonamide vector. 


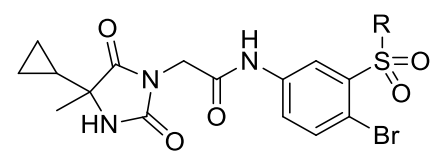

\begin{tabular}{|c|c|c|c|c|c|c|c|}
\hline & $\mathrm{R}$ & $\begin{array}{c}\text { ATAD2 } \\
\text { pIC50 } \\
\text { (n) }\end{array}$ & $\begin{array}{c}\text { ATAD2 } \\
\text { LE / } \\
\text { LLEat }\end{array}$ & $\begin{array}{c}\text { CECR2 } \\
\text { pIC50 (n) } \\
\text { / Sel. }\end{array}$ & $\begin{array}{c}\text { BRD4 } \\
\text { BD1 } \\
\text { pIC50 (n) }\end{array}$ & $\begin{array}{c}\text { Chrom } \\
\text { LogD }\end{array}$ & $\begin{array}{c}\text { CLND } \\
\text { sol. } \\
\left(\mu \mathrm{g} \mathrm{mL}^{-1}\right)\end{array}$ \\
\hline$(S)-31$ & & $6.6(8)$ & $\begin{array}{c}0.30 / \\
0.31\end{array}$ & $\begin{array}{c}6.4(6) / \\
2 x\end{array}$ & $<4.3(2)$ & 4.1 & $>195^{\mathrm{b}}$ \\
\hline $\begin{array}{c}(S, S)- \\
32\end{array}$ & & $7.2(6)$ & $\begin{array}{c}0.32 / \\
0.30\end{array}$ & $\begin{array}{c}6.5(2) / \\
5 x\end{array}$ & $<4.3(2)$ & 4.7 & 129 \\
\hline $\begin{array}{c}(R, S)- \\
32\end{array}$ & & $7.0(8)$ & $\begin{array}{l}0.31 / \\
0.30\end{array}$ & $\begin{array}{c}6.9(4) / \\
1 x\end{array}$ & $<4.3(4)$ & 4.8 & 146 \\
\hline $33^{a}$ & -2 & $7.6(2)$ & $\begin{array}{c}0.30 / \\
0.29\end{array}$ & $\begin{array}{c}6.9(2) / \\
5 x\end{array}$ & $4.4(2)$ & 5.2 & 47 \\
\hline
\end{tabular}

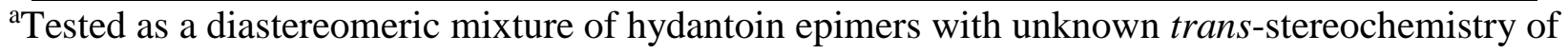
the pyrrolidine substituents; ${ }^{\mathrm{b}} \mathrm{CAD}$ solubility.

A crystal structure of $(\boldsymbol{R}, \boldsymbol{S})-32$, was resolved in ATAD2 (Fig. 3. A-B). The binding mode of $(\boldsymbol{R}, \boldsymbol{S})-32$ was consistent with that of the initial hit (Fig 2). The aromatic bromide sits deep within the binding pocket and displaces the conserved water molecules in ATAD2. The $(S)$-methyl pyrrolidine group occupies a lipophilic pocket surrounded by the conserved Y1021, N1064 and the gatekeeper I1074 residues. The hydantoin carbonyl groups can then be seen making the previously observed H-bonding interactions with the backbone $N H$ of D1014 and R1007. The 
methyl and cyclopropyl groups, which were added to improve permeability, do not appear to pick up any specific contacts, in agreement with the biochemical data generated.
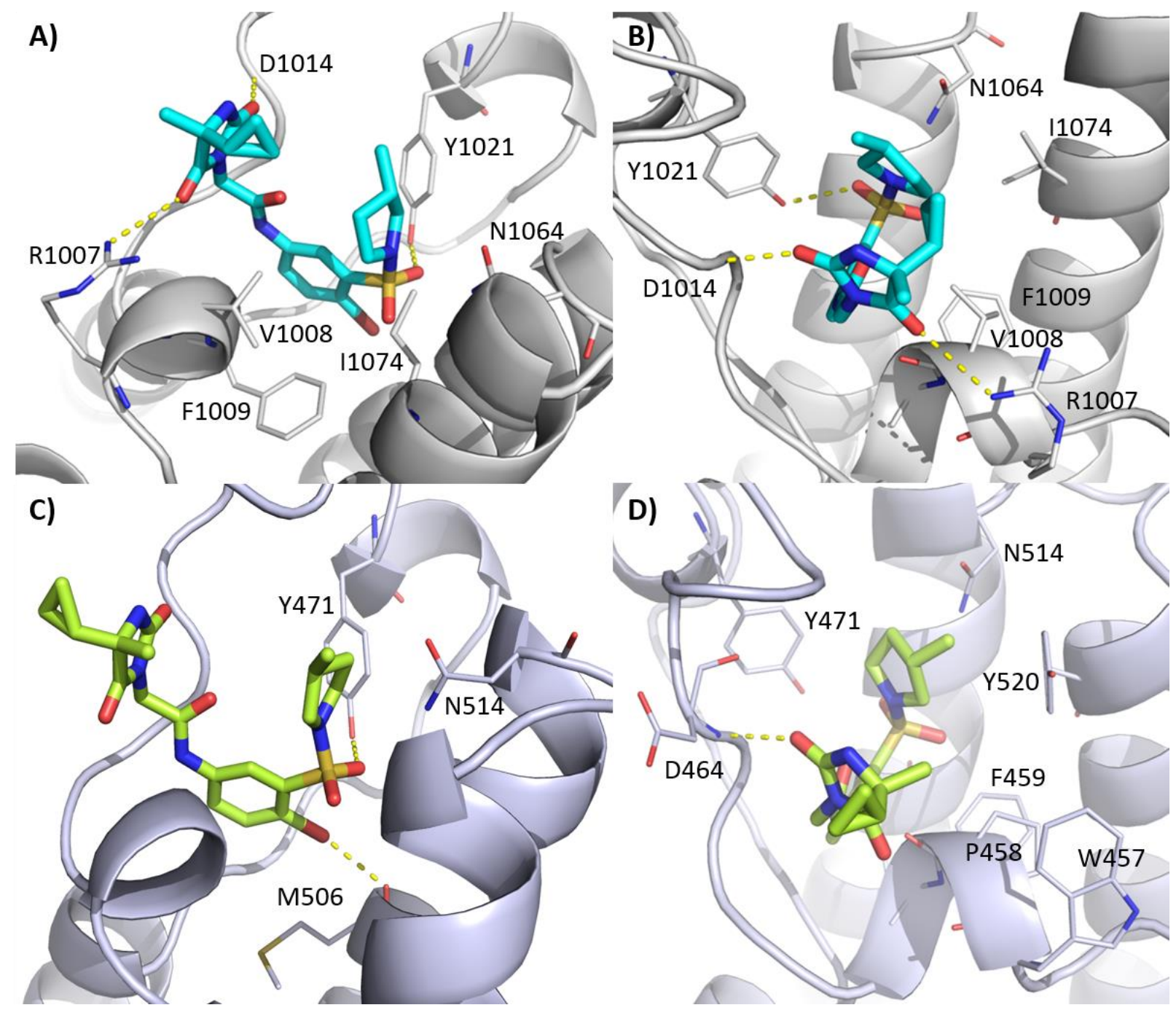

Fig. 3. X-ray crystal structure (pdbXXXX) of $(\boldsymbol{S}, \boldsymbol{R})-\mathbf{3 2}$ (teal) in ATAD2 (silver) and a docking model of $(\boldsymbol{S}, \boldsymbol{S})$-32 (lime) in CECR2 (lilac, pdb3NXB): A) Pose showing $(\boldsymbol{S}, \boldsymbol{R})$-32 sitting deep within the binding pocket, where the ligand displaces the normally conserved water network in the KAc recognition site; B) Rotated pose showing the hydantoin carbonyl groups make H-bonds to both R1007 and D1014 and one of the sulfonamide oxygens makes a H-bond to Y1021; C) pose showing there is space for $(\boldsymbol{S}, \boldsymbol{S})-\mathbf{3 2}$ to displace that waters in CECR2 and make key 
contacts with M506 and Y471. D) Rotated pose showing that (S,S)-32 makes a H-bond to D464 but does not make any specific interactions with the WPF shelf in CECR2.

$(S, S)-32$ represented the most optimised ATAD2 inhibitor to date, boasting excellent potency and a novel mode of binding. To assess the inherent selectivity of this series of inhibitors, the wider bromodomain selectivity of $(\boldsymbol{S}, \boldsymbol{S})$-32 was investigated, firstly, using in house TR-FRET assays and then DiscoverX's full BROMOscan panel (Fig. 4). Pleasingly, (S,S)-32 was >200-fold selectivity over the BET family of bromodomains, using BRD4 as a representitive example. The high potency of $(\boldsymbol{S}, \boldsymbol{S})-32$ was confirmed in the BROMOscan ATAD2A $\left(\mathrm{pK}_{\mathrm{d}}=8.0\right)$ and ATAD2B $\left(\mathrm{pK}_{\mathrm{d}}=7.6\right)$ assays. Significant potency was observed for seven other bromodomains: Bromodomain adjacent to zinc finger domain protein $2 \mathrm{~A}\left(\mathrm{BAZ2A}, \mathrm{pK}_{\mathrm{d}}=7.8\right), \mathrm{BRD} 1\left(\mathrm{pK}_{\mathrm{d}}=6.9\right)$, Bromodomain and PHD finger-containing protein $3\left(\mathrm{BRPF} 3, \mathrm{pK}_{\mathrm{d}}=6.9\right)$, CECR2 $\left(\mathrm{pK}_{\mathrm{d}}=7.6\right)$, general control nonderepressible $5\left(\mathrm{GCN} 5 \mathrm{~L} 2, \mathrm{pK}_{\mathrm{d}}=6.6\right)$, TATA-binding protein-associated factor 1 (TAF1(2), $\left.\mathrm{pK}_{\mathrm{d}}=7.8\right)$ and TAF1-like (TAF1L(2), $\left.\mathrm{pK}_{\mathrm{d}}=7.6\right)$ bromodomains. Greater than 30-fold selectivity was observed for all other bromodomains tested against. Interestingly, the stability of the water network in these bromodomains has previously been predicted to vary greatly, therefore, this level of off-target activity was suprising. ${ }^{41}$ It may suggest that displacement of the canonical waters is a viable approach for multiple targets in the future. Cellular target engagement was demonstrated using a CECR2 nanoBRET assay, in which a fluorescent bromosporine ligand was competitively displaced from CECR2 in HEK293 cells. ${ }^{42}(\boldsymbol{S}, \boldsymbol{S})-\mathbf{3 2}$ showed activity (pIC50 = 6.5) in concordance with it's CECR2 potency, demonstrating its ability to engage a cellular target. Overall $(\boldsymbol{S}, \boldsymbol{S})$-32 was identified as a potent ATAD2 inhibitor with good physicochemical profile and evidence of cellular target engagement. Given the historical difficulties with achieving highly potent ATAD2 
inhibitors, the unique binding mode and novel chemotype will make (S,S)-32 (GSK388) an important addition to the ATAD2 chemical toolbox.

Table 5. Profile of $(S, S)-32$

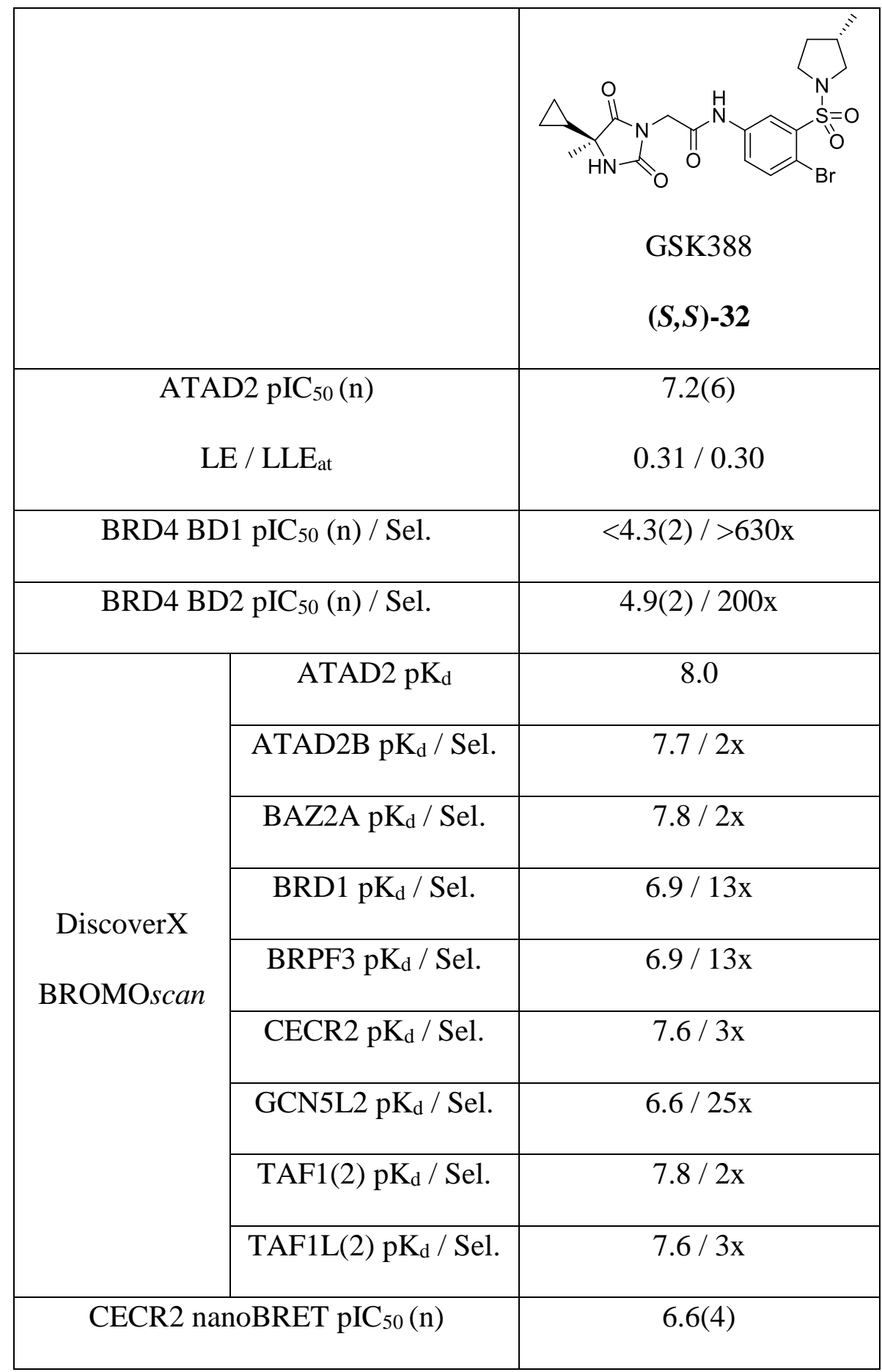




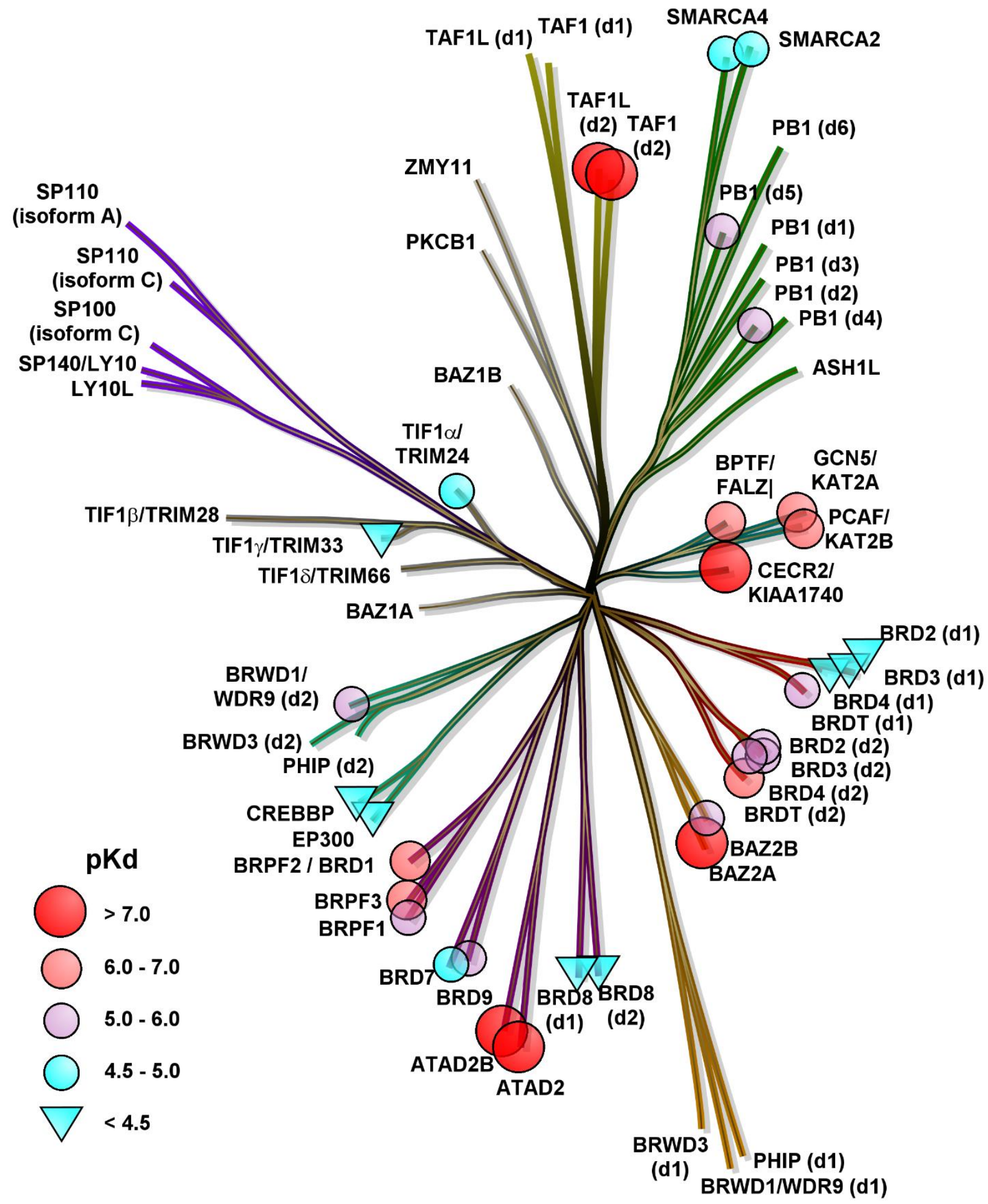

Fig. 4. DiscoverX's BROMOscan results of (S)-32. 


\section{Optimisation towards a CECR2 selective inhibitor:}

Having optimised our phenyl sulfonamide series for ATAD2 potency, it was intriguing that potency at CECR2 (and indeed 7 other bromodomains) had not been reduced more significantly. A docking of $(S, S)-32$ in the apo structure of CECR2 (pdb3NXB) was solved to aid understanding of the differences between the two proteins (Fig. 3. C-D). ${ }^{43}$ Despite computational evidence that the water network in CECR2 is more stable than in ATAD2, ${ }^{41}$ the binding pocket of CECR2 still appears able to accommodate $(\boldsymbol{S}, \boldsymbol{S})$-32. Indeed, considering the trends in SAR observed previously, we were confident that the phenyl sulfonamide ligands were binding to both bromodomains through displacement of the canonical waters. The sulfonamide is positioned so that one of the sulfonamide oxygens can make a H-bond interaction with Y471 and the aryl bromide can make a halogen bond to the carbonyl group of M506 (the CECR2 residue analogous

to 11056 in ATAD2). The $(S)$-methyl pyrrolidine then occupies a lipophilic pocket formed of Y471, N514 and Y520. When compared with the crystal structure of ATAD2, several notable residue changes were apparent (Fig. 5). Firstly, the I1074 gatekeeper residue in ATAD2 is replaced by Y520 in CECR2. In ATAD2 the (RVF) shelf region is formed from R1007, V1008 and F1009, compared to W457, P458 and F459 in CECR2 which form a WPF shelf. It was hypothesised that these residue changes could be exploited to obtain enhanced CECR2 potency and selectivity. 


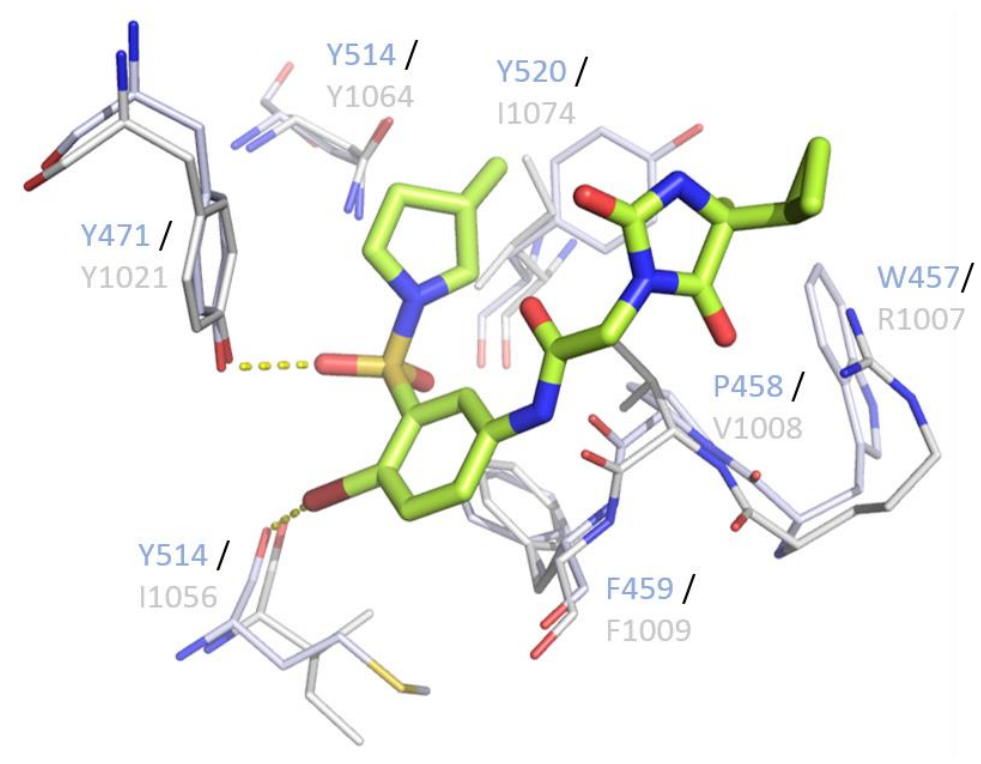

Fig. 4. A docking model of $(\boldsymbol{S}, \boldsymbol{R})$-32 (lime) in the apo crystal structure of CECR2 with point changes between the CECR2 (lilac) and ATAD2 (grey) domains annotated.

In ATAD2, the hydantoin makes H-bonds using both carbonyl groups; one to the backbone NH of D1014 and the other to the flexible sidechain of R1007 on the RVF shelf (Fig. 3. A-B). In CECR2, according to the model, one of the hydantoin carbonyl groups can still make a H-bond to the backbone $\mathrm{NH}$ of D464. However, there is no suitable donor for the other carbonyl group on the WPF region due to the residue change from R1007 to W457. SAR work had shown that the two carbonyl groups were vital for ATAD2 potency and that moderate selectivity for CECR2 could be gained through removal of one of them, albeit with a significant reduction in potency (Table 3 ). Therefore, a strategy was adopted which aimed to build out towards the WPF residues with a substituent which could interact favourably with W457 in CECR2.

Aromatic rings have been shown to form $\pi$-stacking interactions with the WPF shelf in the BET family. ${ }^{44}$ Whilst the shelf in CECR2 is blocked by the gatekeeper Y520, it was hypothesised that substituents such as benzimidazolinone (S)-34 (Table 6) might still interact with W457 whilst 
maintaining a H-bond with the backbone $\mathrm{NH}$ of D464. This would also remove one of the carbonyl groups which had appeared crucial for ATAD2 activity, hopefully leading to an increase in selectivity. Pleasingly, benzimidazolinone $(\boldsymbol{S})$-34 maintained potency at CECR2 $\left(\mathrm{pIC}_{50}=6.4\right)$ relative to hydantoin $(\boldsymbol{S}, \boldsymbol{S})$-32 whilst activity at ATAD2 dropped 20-fold. The corresponding benzoxazolidine $(\boldsymbol{S})$-35 showed a further 10-fold increase in potency towards CECR2 $\left(\mathrm{pIC}_{50}=\right.$ 7.4) and 5-fold selectivity over ATAD2. There was only a marginal increase in $\operatorname{LLE}_{\text {at }}$ for $(\boldsymbol{S})-\mathbf{3 5}$ relative to $(\boldsymbol{S}, \boldsymbol{S})-\mathbf{3 2}$, due to the raised lipophilicity of this analogue. Compound $(S)-35$ was also more potent at BRD4 BD1 $\left(\mathrm{pIC}_{50}=5.0\right)$ although it still maintained a 250 -fold selectivity window. Based on previously discussed ATAD2 crystallography and CECR2 modelling (vide supra), it was hypothesised that the carbamate in $(\boldsymbol{S}, \boldsymbol{R})-\mathbf{3 5}$ retained a H-bonding interaction with both proteins. Benzotriazole $(S)$-36 and benzisoxazole $(S)$-37 were designed to explore whether this interaction could be maintained when the H-bond acceptor was located within an aromatic ring. Both compounds showed good potency for CECR2 $\left(\mathrm{pIC}_{50}=6.7\right.$ and 6.6 respectively) and maintained a bias over ATAD2 and high selectivity over BRD4 BD1. Removal of one of the heteroatoms to give benzofuran $(\boldsymbol{S})$-38 showed a 32-fold drop-off in CECR2 potency, suggesting that a H-bond acceptor at the 2-position was crucial. Unfortunately, compounds $\mathbf{3 4 - 3 8}$ showed reduced solubility ( $\leq 25 \mu \mathrm{g} \mathrm{mL}^{-1}$ ), most likely due to their greater lipophilicity and aromaticity. As a result, none of the compounds tested were ideal tool molecules. 
Table 6. Targeting the WPF shelf of CECR2.

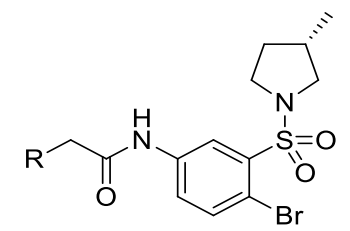

\begin{tabular}{|c|c|c|c|c|c|c|c|}
\hline & $\mathbf{R}$ & $\begin{array}{l}\text { CECR2 } \\
\operatorname{pIC}_{50}(n)\end{array}$ & $\begin{array}{c}\text { CECR2 } \\
\text { LE / } \\
\text { LLEat }^{2}\end{array}$ & $\begin{array}{c}\text { ATAD2 } \\
\operatorname{pIC}_{50}(n) \\
\text { / Sel. }^{\mathrm{a}}\end{array}$ & $\begin{array}{c}\text { BRD4 } \\
\text { BD1 } \\
\text { pIC50 } \\
\text { (n) }\end{array}$ & $\begin{array}{c}\text { Chrom } \\
\text { LogD }\end{array}$ & $\begin{array}{c}\text { CAD } \\
\text { Sol. } \\
(\mu \mathrm{g} \\
\left.\mathrm{mL}^{-1}\right)\end{array}$ \\
\hline $\begin{array}{l}(S, S) \\
-32\end{array}$ & & $6.5(2)$ & $\begin{array}{l}0.30 / \\
0.28\end{array}$ & $\begin{array}{l}7.2(6) / \\
5 \times(A)\end{array}$ & $<4.3(2)$ & 4.7 & $129^{c}$ \\
\hline $\begin{array}{l}(S)- \\
34\end{array}$ & & 6.3(4) & $\begin{array}{c}0.29 / \\
0.23\end{array}$ & $\begin{array}{c}5.9(6) / \\
3 x\end{array}$ & $<4.3(3)$ & 4.6 & 25 \\
\hline $\begin{array}{l}(S)- \\
35\end{array}$ & & $7.2(4)$ & $\begin{array}{l}0.34 / \\
0.29\end{array}$ & $\begin{array}{c}5.7(4) / \\
32 \mathrm{x}\end{array}$ & $5.0(2)$ & 5.7 & 21 \\
\hline $\begin{array}{l}(S)- \\
36\end{array}$ & & $6.7(4)$ & $\begin{array}{l}0.32 / \\
0.26\end{array}$ & $\begin{array}{c}5.7(4) / \\
10 \mathrm{x}\end{array}$ & $4.8(1)^{\mathrm{b}}$ & 5.3 & 18 \\
\hline $\begin{array}{l}(S)- \\
37\end{array}$ & & $6.6(6)$ & $\begin{array}{l}0.31 / \\
0.26\end{array}$ & $\begin{array}{c}6.0(4) / \\
4 x\end{array}$ & $4.6(1)^{\mathrm{b}}$ & 6.2 & $3^{c}$ \\
\hline $\begin{array}{l}(S)- \\
38\end{array}$ & & $5.1(5)$ & $\begin{array}{l}0.24 / \\
0.14\end{array}$ & $\begin{array}{l}5.6(2) / \\
3 \times(\mathrm{A})\end{array}$ & $<4.3(2)$ & 6.7 & $0^{\mathrm{c.d}}$ \\
\hline
\end{tabular}

${ }^{\text {a }}$ A) denotes selectivity for ATAD2 over CECR2; ${ }^{b}$ Data is $<4.3$ on $1 / 2$ test occasions; ${ }^{\text {c CLND }}$ solubility; ${ }^{\mathrm{d}}$ Data is $<0$ on $1 / 2$ test occasions. 
Whilst the use of an aromatic amide substituent increased potency and selectivity at CECR2 it was unclear whether this was indeed the optimal substituent. To investigate the requirement for the phenyl ring of the benzotriazole $(\boldsymbol{S})$-36 was truncated. Unsubstituted triazole (S)-39 (Table 7) showed weak CECR2 potency (c.f. benzotriazole $(\boldsymbol{S})$-36) but maintained ligand efficiency compared to the leading biaryls (34-37). It was therefore logical to investigate alternate substituents to look for improved physicochemical properties whilst maintaining the potency of benzotriazole $(\boldsymbol{S})$-36. Dimethyltriazole $(\boldsymbol{S})-\mathbf{4 0}$ showed increased CECR2 inhibition $\left(\mathrm{pIC}_{50}=6.0\right)$ whilst maintaining the ligand efficiency and ATAD2 selectivity of $(\boldsymbol{S})$-39. This suggested that the aromatic ring could be replaced by $\mathrm{sp}^{3}$ groups with similar overall efficiency. A diversity orientated approach which initially looked at range of substitution at the 4-position was undertaken and the key examples are discussed herein. Neither a propyl or ether group increased affinity for CECR2 ((S)-41 and (S)-42), but, the installation of a methylene linked dimethylamine afforded $(\boldsymbol{S})-\mathbf{4 3}\left(\mathrm{pIC}_{50}=6.6\right)$, a potent CECR2 inhibitor which was 5-fold selective over ATAD2. $(\boldsymbol{S})-\mathbf{4 3}$ was equipotent with benzotriazole $(\boldsymbol{S})$-36 but significantly less lipophilic and highly soluble ( $\geq 234$ $\left.\mu \mathrm{g} \mathrm{mL}^{-1}\right)$. The same substituents at the 5-position were then prepared and interestingly, all three analogues (44-46) showed increased potency for CECR2 and improved selectivity over ATAD2. In particular, dimethylamine $(\boldsymbol{S})-\mathbf{4 6}$ displayed 50 -fold selectivity for CECR2 $\left(\mathrm{pIC}_{50}=7.1\right)$. Importantly, it was also soluble ( $\left.\geq 219 \mu \mathrm{g} \mathrm{mL}^{-1}\right)$ and therefore demonstrated, for the first time, that desirable CECR2 potency and selectivity were possible with compounds with a suitable physicochemical profile. 
Table 7. Investigating triazole substitution.

\begin{tabular}{|c|c|c|c|c|c|c|c|}
\hline & $\mathbf{R}$ & $\begin{array}{l}\text { CECR2 } \\
\operatorname{pIC}_{50}(n)\end{array}$ & $\begin{array}{c}\text { CECR2 } \\
\text { LE / } \\
\text { LLEat }\end{array}$ & $\begin{array}{c}\text { ATAD2 } \\
\text { pIC50 (n) } \\
\text { /Sel. }^{\mathrm{a}}\end{array}$ & $\begin{array}{c}\text { BRD4 } \\
\text { BD1 } \\
\text { pIC50 (n) }\end{array}$ & $\begin{array}{c}\text { Chrom } \\
\operatorname{LogD}\end{array}$ & $\begin{array}{c}\text { CAD } \\
\text { Sol. } \\
\left(\mu \mathrm{g} \mathrm{mL}^{-1}\right)\end{array}$ \\
\hline $\begin{array}{l}(S)- \\
39\end{array}$ & 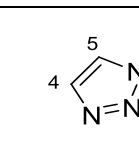 & $5.4(6)$ & $\begin{array}{l}0.30 / \\
0.30\end{array}$ & $\begin{array}{c}5.4(6) / \\
-\end{array}$ & $<4.3(2)$ & 3.9 & $\geq 166$ \\
\hline $\begin{array}{l}(S)- \\
40\end{array}$ & & $6.0(6)$ & $\begin{array}{l}0.30 / \\
0.30\end{array}$ & $\begin{array}{c}5.2(6) / \\
6 x\end{array}$ & $<4.3(2)$ & 4.4 & $\geq 181$ \\
\hline $\begin{array}{l}(S)- \\
41\end{array}$ & & $5.8(6)$ & $\begin{array}{l}0.28 / \\
0.24\end{array}$ & $\begin{array}{c}5.8(6) / \\
-\end{array}$ & $4.4(2)$ & 5.1 & 48 \\
\hline $\begin{array}{l}\text { (S)- } \\
42\end{array}$ & -0 & $5.8(6)$ & $\begin{array}{l}0.28 / \\
0.31\end{array}$ & $\begin{array}{c}5.6(8) / \\
2 \mathrm{x}\end{array}$ & $<4.3(2)$ & 4.1 & $\geq 235$ \\
\hline $\begin{array}{l}(S)- \\
43\end{array}$ & $-N$ & $6.6(4)$ & $\begin{array}{l}0.31 / \\
0.34\end{array}$ & $\begin{array}{c}5.9(6) / \\
5 \mathrm{x}\end{array}$ & $<4.3(2)$ & 3.1 & $\geq 234$ \\
\hline $\begin{array}{l}(S)- \\
44\end{array}$ & & $7.1(5)$ & $\begin{array}{l}0.35 / \\
0.30\end{array}$ & $\begin{array}{c}5.5(6) / \\
40 \mathrm{x}\end{array}$ & $5.0(1)$ & 5.1 & 19 \\
\hline $\begin{array}{l}(S)- \\
45\end{array}$ & $N=1$ & $6.6(6)$ & $\begin{array}{l}0.32 / \\
0.35\end{array}$ & $\begin{array}{c}6.0(6) / \\
4 x\end{array}$ & $<4.3(1)^{\mathrm{a}}$ & 4.3 & $\geq 216$ \\
\hline
\end{tabular}




\begin{tabular}{|c|c|c|c|c|c|c|c|}
\hline $\begin{array}{l}(S)- \\
46\end{array}$ & $\sum_{\substack{N \\
N}}^{N}$ & $7.1(5)$ & $\begin{array}{l}0.34 / \\
0.37\end{array}$ & $\begin{array}{c}5.4(6) / \\
50 x\end{array}$ & $<4.3(2)$ & 4.5 & $\geq 219$ \\
\hline
\end{tabular}

${ }^{\mathrm{a}}$ Data is $<4.3$ on $1 / 2$ test occasions.

Building on the success of the secondary amine derivatives, and the tolerance of substitution at both the 4- and 5-positions, we wanted to explore the effect of conformationally restricting the dimethylamine group. To do this, a range of triazolopiperidines (47-53, Table 8) were prepared. $(S)-46$ had afforded higher potency relative to its regioisomer, $(S)-43$ (Table 7$)$. Therefore, conformational restriction of this amine was investigated first. Interestingly, triazolopiperidine $(S)$ 47 was $0.4 \log$ units less potent at CECR2 $\left(\mathrm{pIC}_{50}=6.7\right)$ relative to dimethylamine $(\boldsymbol{S})-46$ suggesting that conformational restriction did not maintain the dimethylamine in its favoured binding conformation. Regioisomeric triazolopiperidine $(\boldsymbol{S})$-48 was prepared and pleasingly, was both highly potent $\left(\mathrm{CECR} 2 \mathrm{pIC}_{50}=7.3\right)$ and 40-fold selective for CECR2. Additionally, $(\boldsymbol{S})-\mathbf{4 8}$ had a low ChromLogD (3.7) and was highly soluble ( $\left.\geq 211 \mu \mathrm{g} \mathrm{mL}^{-1}\right)$. The methyl group could be extended to give ethylamine $(S)-49$ which had a comparable profile to $(S)-48$ albeit with a slight increase in ChromLogD. Branching of the alkyl group gave isopropyl amine $(\boldsymbol{S})-\mathbf{5 0}$ which was also highly potent at CECR2 $\left(\mathrm{pIC}_{50}=7.6\right)$, equating to 79 -fold selectivity over ATAD2. Despite the increased lipophilicity compared to $(\boldsymbol{S}) \mathbf{- 4 8},(\boldsymbol{S})-\mathbf{4 9}$ and $(\boldsymbol{S})-\mathbf{5 0}$ were still highly soluble (>238 $\left.\mu \mathrm{g} \mathrm{mL}{ }^{-1}\right)$. In an effort to further understand the tolerated substitution of the amine, trifluoroethylamine $(\boldsymbol{S})$-51 was tested. A $0.5 \log$ unit reduction in CECR2 potency was observed relative to ethylamine $(S)-49$. The increased lipophilicity of $(S)-51$ was also detrimental to the solubility $\left(49 \mu \mathrm{g} \mathrm{mL}^{-1}\right)$. Acylation of the amine gave acetamide $(\boldsymbol{S})$-52 which was potent at CECR2 $\left(\mathrm{pIC}_{50}=7.0\right)$ but was only 16 -fold selective over ATAD2. The unsubstituted triazolopiperidine 
$(\boldsymbol{S})$-53 was poorly tolerated in CECR2 $\left(\mathrm{pIC}_{50}=6.6\right)$ but still maintained a 10 -fold selectivity window. Overall, whilst there seemed scope to extend from the -NMe to larger substituents, $(\boldsymbol{S})$ 48 already exhibited a highly promising profile worthy of further investigation.

Table 8. Investigation the SAR of triazolopiperidines.

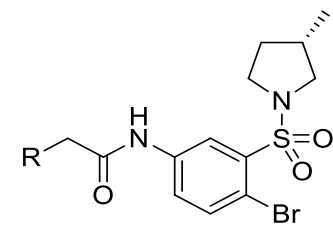

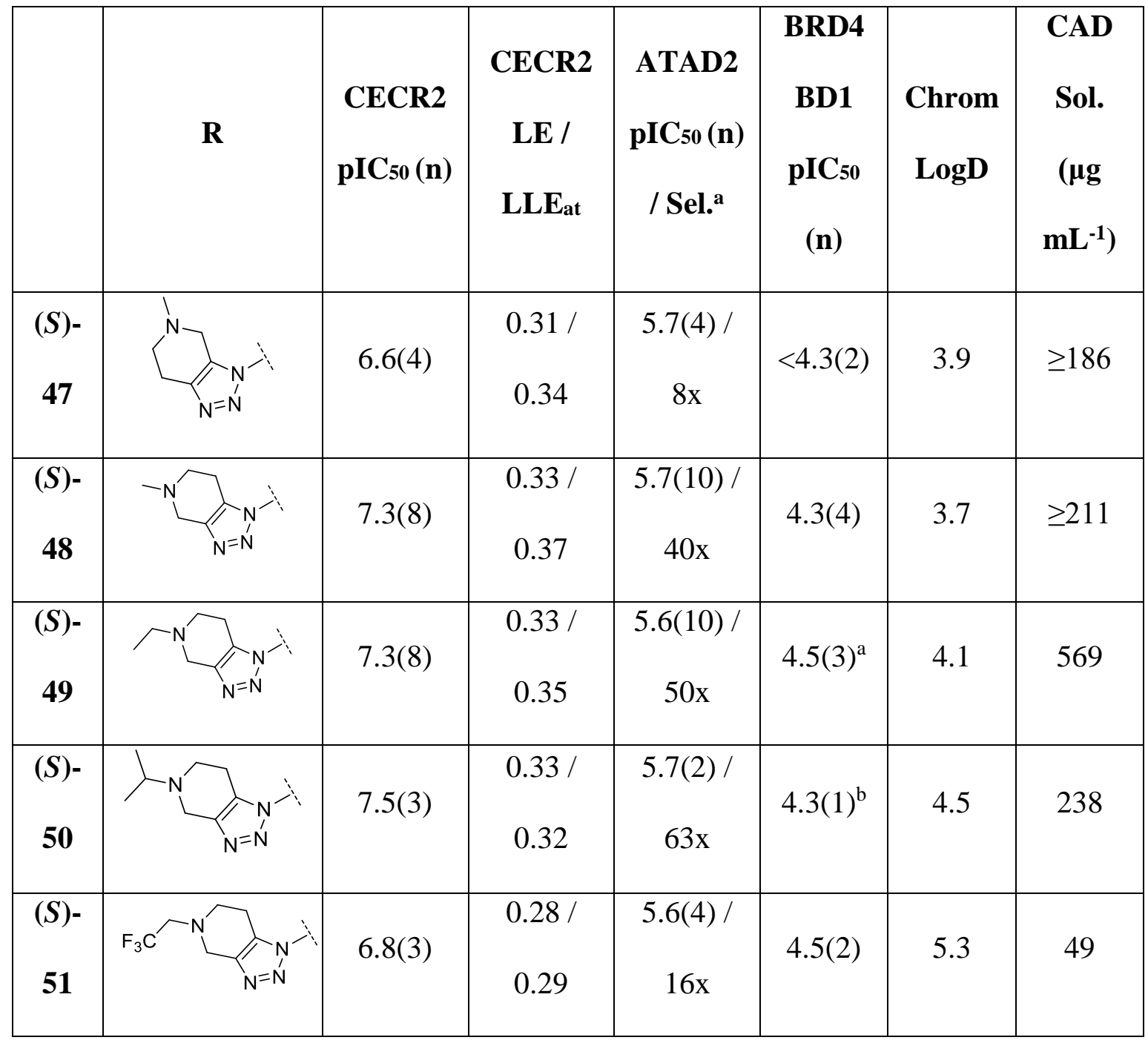




\begin{tabular}{|c|c|c|c|c|c|c|c|}
\hline $\begin{array}{l}(S)- \\
52\end{array}$ & $\lambda_{N=N}^{N}$ & 7.0(3) & $\begin{array}{l}0.30 / \\
0.41\end{array}$ & $\begin{array}{c}5.8(4) / \\
16 \mathrm{x}\end{array}$ & $<4.3(2)$ & 3.4 & 182 \\
\hline $\begin{array}{l}(S)- \\
53\end{array}$ & & $6.6(5)$ & $\begin{array}{l}0.31 / \\
0.37\end{array}$ & $\begin{array}{c}5.6(6) / \\
10 \mathrm{x}\end{array}$ & $4.8(2)$ & 2.9 & $\geq 233$ \\
\hline
\end{tabular}

${ }^{\mathrm{a}}$ Data is $<4.3$ on $1 / 4$ test occasions; ${ }^{\mathrm{b}}$ Data is $<4.3$ on $1 / 2$ test occasions.

Having identified triazolopiperidines as suitable CECR2 selective inhibitors, the sulfonamide vector was revisited with respect to CECR2. As discussed previously, 3-cyclopropyl pyrrolidine (rac)-20 was 6-fold more potent at CECR2 relative to $(S)$-methyl pyrrolidine $(\boldsymbol{S})$-13 (Table 2). This sulfonamide was therefore prepared with the optimised triazolopiperidine. Due to the predicted increase in both potency and lipophilicity, both the chloride and bromide aryl substituents were prepared (Table 9). The enantiomers were separated by preparative chiral HPLC and identified by vibrational circular dichroism. As predicted, the switch from methyl to cyclopropyl led to a $0.9 \log$ unit increase in potency for the most active enantiomer $((\boldsymbol{R})$-54) relative to $(\boldsymbol{S})$-48. Interestingly, the opposite enantiomer was 20 -fold less potent at CECR2, a trend which was also observed for $(\boldsymbol{R}) \mathbf{- 5 5} v s$. $(\boldsymbol{S})$-55. This is significant as both enantiomers of methyl pyrrolidine $((\boldsymbol{R})$-13 and $(\boldsymbol{S})$-13) were equipotent at CECR2 (Table 2). It is likely that the increased size of the cyclopropyl group means that the pocket is more accommodating to one enantiomer than the other. Pleasingly, despite the increased lipophilicity (ChromLogD $=4.4),(\boldsymbol{R})-54$ maintained high solubility $\left(177 \mu \mathrm{g} \mathrm{mL} L^{-1}\right)$. In line with previous $\mathrm{SAR},{ }^{33}$ the chloride analogue was $0.5 \log$ units less potent than the bromide. However, in combination with the cyclopropyl pyrrolidine, $(\boldsymbol{R})$-55 had a high CECR2 pIC $_{50}$ of 7.7, was 160-fold selective over ATAD2, 1300fold selective over BRD4 BD1 and highly soluble $\left(207 \mu \mathrm{g} \mathrm{mL} \mathrm{L}^{-1}\right)$. Both $(\boldsymbol{R})-\mathbf{5 4}$ and $(\boldsymbol{R})-55$ were 
therefore nominated for further profiling of their wider bromodomain selectivity and cellular target engagement (vida infra).

Table 9. Combining sulfonamide SAR with an optimised triazolopiperidine.

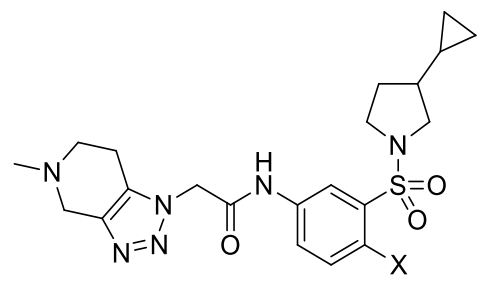

\begin{tabular}{|c|c|c|c|c|c|c|c|}
\hline $\begin{array}{c}\text { Cmpd } \\
\text { No. }\end{array}$ & $\mathbf{X}$ & $\begin{array}{l}\text { CECR2 } \\
\operatorname{pIC}_{50}(n)\end{array}$ & $\begin{array}{c}\text { CECR2 } \\
\text { LE / } \\
\text { LLEat }\end{array}$ & $\begin{array}{c}\text { ATAD2 } \\
\text { pIC50 (n) } \\
\text { /Sel. }^{\mathrm{a}}\end{array}$ & $\begin{array}{c}\text { BRD4 } \\
\text { BD1 } \\
\text { pIC50 (n) }\end{array}$ & $\begin{array}{c}\text { Chrom } \\
\text { LogD }\end{array}$ & $\begin{array}{c}\text { CAD } \\
\text { Sol. } \\
\left(\mu \mathrm{g} \mathrm{mL}^{-1}\right)\end{array}$ \\
\hline$(R)-54$ & & $8.2(3)$ & $0.36 / 0.38$ & $\begin{array}{l}5.7(4) / \\
320 \mathrm{x}\end{array}$ & $4.9(2)$ & 4.4 & 177 \\
\hline$(S)-54$ & & 7.4(3) & $0.32 / 0.35$ & $\begin{array}{c}5.5(4) / \\
79 \mathrm{x}\end{array}$ & $4.6(2)$ & 4.4 & 248 \\
\hline$(R)-55$ & & $7.7(4)$ & $0.35 / 0.38$ & $\begin{array}{l}5.5(2) / \\
160 \mathrm{x}\end{array}$ & 4.6(4) & 4.3 & 207 \\
\hline$(S)-55$ & & $6.9(3)$ & $0.30 / 0.32$ & $\begin{array}{c}5.2(4) / \\
50 \mathrm{x}\end{array}$ & $4.4(2)$ & 4.3 & $\geq 312$ \\
\hline
\end{tabular}

\section{Chemistry:}

The phenyl sulfonamides were typically constructed using the chemistry detailed in scheme 1 which shows the synthesis of $(\boldsymbol{S}, \boldsymbol{S})$-32. The commercially available sulfonyl chloride $\mathbf{5 6}$ was reacted with $(S)$-methyl pyrrolidine under basic conditions to afford sulfonamide $(\boldsymbol{S})$-57 in $\mathbf{9 0 \%}$ 
yield. The nitro group was reduced to aniline $(\boldsymbol{S})$-58 using iron and ammonium chloride in $98 \%$ yield. An amide coupling with the commercially available racemic carboxylic acid then introduced the hydantoin substituent to give $(\boldsymbol{S}, \boldsymbol{S})$-32 after separation of the two diastereoisomers.

Scheme 1. Synthesis of $(S, S)-32$

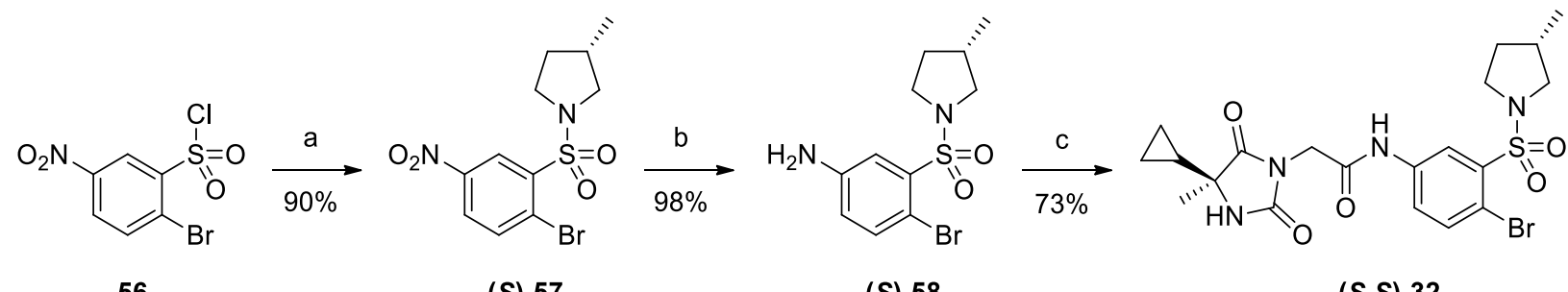
56

(S)-57

(S)-58

(S,S)-32

Reagents and conditions: a) (S)-methylpyrrolidine hydrochloride (1.0 eq.), DIPEA (2.2 eq.), $\mathrm{CH}_{2} \mathrm{Cl}_{2}, 0{ }^{\circ} \mathrm{C}, 1 \mathrm{~h}, 90 \%$; b) iron (5.0 eq.), $\mathrm{NH}_{4} \mathrm{Cl}$ (1.5 eq.), EtOH:water (3:1), $70{ }^{\circ} \mathrm{C}, 2 \mathrm{~h}, 98 \%$; c) ( \pm )-2-(4-cyclopropyl-4-methyl-2,5-dioxoimidazolidin-1-yl)acetic acid (1.1 eq.), DIPEA (3.0 eq.), T3P (50\% $w / w$ in EtOAc, 1.0 eq.), $\mathrm{CH}_{2} \mathrm{Cl}_{2}, \mathrm{rt}, 2 \mathrm{~h}, 73 \%$ then chiral purification.

High throughput array chemistry was utilised to explore the sulfonamide vector. In this case sulfonyl chloride 64 was synthesised as a late stage intermediate (Scheme 2). The aromatic nitro group of $\mathbf{5 9}$ was reduced using iron and ammonium chloride to afford aniline $\mathbf{6 0}$ in 88\% yield. This was then acylated using 2-chloroacetyl chloride to afford alkyl chloride $\mathbf{6 1}$ in $88 \%$ yield. Subsequent alkylation using the commercial hydantoin under basic conditions gave $\mathbf{6 2}$ as a single regioisomer. A palladium $\left(\mathrm{Pd}_{2} \mathrm{dba}_{3}\right.$, xantphos) catalysed thioetherification with benzylthiol gave sulfide 63 in good yield, ${ }^{45}$ which was then oxidised using 1,3-dichloro-5,5-dimethylimidazolidine2,4-dione to afford sulfonyl chloride $\mathbf{6 4}$ in 5-steps with $16 \%$ overall yield. ${ }^{46}$ This could then be used in a series of DIPEA mediated sulfonamidations to synthesise the desired products (9-21, 23). 
Scheme 2. Synthesis of a late stage sulfonyl chloride for use in a sulfonamide array.

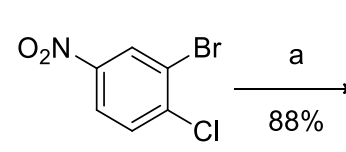

59

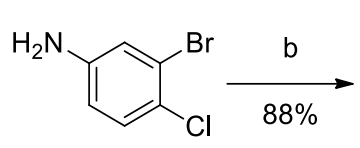

60

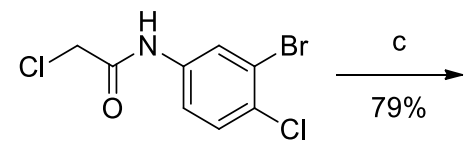

61

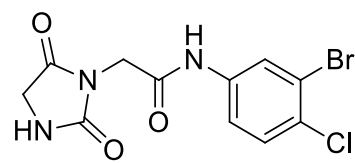

62

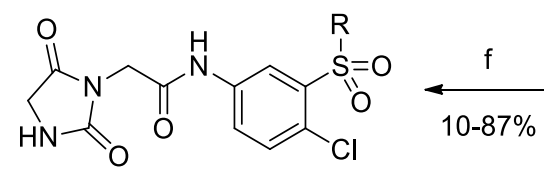

9-21, 23

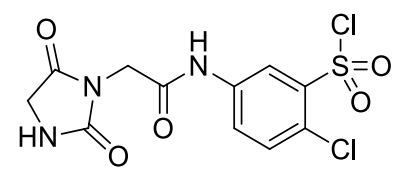

64 $\downarrow \begin{gathered}d \\ 77 \%\end{gathered}$
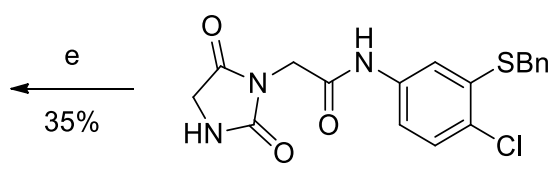

63

Reagents and conditions: a) iron (3.0 eq.), $\mathrm{NH}_{4} \mathrm{Cl}$ (1.5 eq.), EtOH:water $(3: 1), 70{ }^{\circ} \mathrm{C}, 16 \mathrm{~h}, 88 \%$; b) 2-chloroacetyl chloride (1.0 eq.), DIPEA (1.0 eq.), $\mathrm{CH}_{2} \mathrm{Cl}_{2}, \mathrm{rt}, 1 \mathrm{~h}, 88 \%$; c) hydantoin (1.2 eq.), $\mathrm{K}_{2} \mathrm{CO}_{3}$ (3.0 eq.), DMF, $70{ }^{\circ} \mathrm{C}, 1 \mathrm{~h}, 79 \%$; d) benzylthiol (1.5 eq.), xantphos (20 mol\%), $\mathrm{Pd}_{2} \mathrm{dba}_{3}$ (10 mol\%), DIPEA (3.0 eq.), 1,4-dioxane:DMF (3:2), $100{ }^{\circ} \mathrm{C}, 1 \mathrm{~h}, 77 \%$; e) 1,3-dichloro-5,5dimethylimidazolidine-2,4-dione (2.0 eq.), water, $\mathrm{AcOH}, \mathrm{MeCN}, \mathrm{rt}, 2$ h, 35\%; f) amine (2.0 eq.), DIPEA (3.0 eq.), $\mathrm{CH}_{2} \mathrm{Cl}_{2}, \mathrm{rt}, 4 \mathrm{~h}, 10-87 \%$.

In our exploration of the triazole template, click chemistry was employed to regioselectively synthesise the desired analogues (Scheme 3). Late-stage azide ( $\boldsymbol{S}$ )-65 was prepared from aniline (S)-58 and 2-azidoacetic acid using a HATU mediated amide coupling in 94\% yield. A copper catalysed click reaction with the desired alkyne gave 4-substituted triazoles 41-43 in up to $59 \%$ yield. ${ }^{47}$ Alternatively, a ruthenium catalysed click reaction gave the 5substituted triazoles $\mathbf{4 0}$ and $\mathbf{4 4 - 4 6}$ in up to $62 \%$ yield. $^{48}$ 
Scheme 3. Synthesis of triazoles $\mathbf{4 0 - 4 6}$ using either copper or ruthenium catalysed click chemistry.

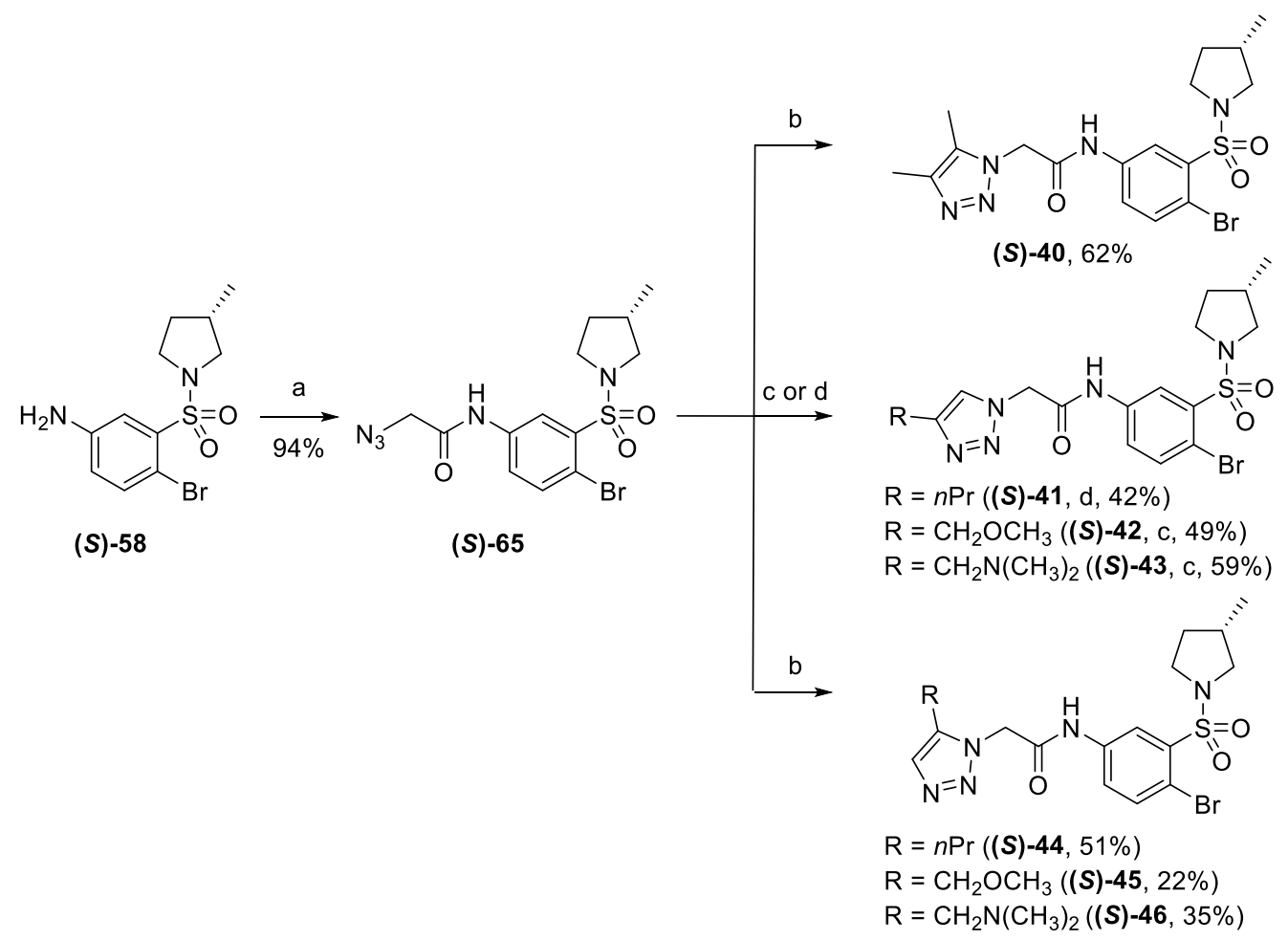

Reagents and conditions: a) 2-Azidoacetic acid (1.0 eq.), HATU (1.2 eq.), DIPEA (3.0 eq.), $\mathrm{CH}_{2} \mathrm{Cl}_{2}$, rt, 2 h, $94 \%$; b) alkyne (1.5 eq.), $\mathrm{Cp} * \mathrm{RuCl}\left(\mathrm{PPh}_{3}\right)_{2}(3 \mathrm{~mol} \%)$, THF, $65{ }^{\circ} \mathrm{C}, 2 \mathrm{~h}, 22-82 \%$. c) alkyne (1.1 eq.), $\mathrm{CuSO}_{4} \cdot 5 \mathrm{H}_{2} \mathrm{O}$ (5 mol\%), sodium ascorbate (0.15 eq.), $\mathrm{CH}_{2} \mathrm{Cl}_{2}$ :water (1:1), $\mathrm{rt}$, $16 \mathrm{~h}, 49-59 \%$; d) alkyne (2.0 eq.), $\mathrm{Cu}(\mathrm{OAc})_{2} \cdot \mathrm{H}_{2} \mathrm{O}$ (10 mol\%), sodium ascorbate (0.15 eq.), $\mathrm{MeOH}, 100{ }^{\circ} \mathrm{C}$, mw, $30 \mathrm{~min}, 42 \%$;

The chemistry to generate the CECR2 selective triazolopiperidine $(\boldsymbol{R})$-55 was more complex, as it involved synthesis of the triazolopyridine coupling partner 69 in the first instance (Scheme 4). Starting from the commercially available pyridine $\mathbf{6 6}$, an $\mathrm{S}_{\mathrm{N}} \mathrm{Ar}$ using tert-butyl glycinate gave ester 67. Reduction of the nitro group to the aniline was facilitated using the conditions outlined previously (c.f. schemes 1 and 2) and reaction of $\mathbf{6 8}$ with sodium nitrite under 
acidic conditions gave the desired triazolopyridine 69 in $37 \%$ yield. ${ }^{49}$ This was hydrolysed under acidic ( $\mathrm{HCl}, 4 \mathrm{M}$ in 1,4-dioxane) conditions and coupled to aniline (rac)-72 using HATU and DIPEA to afford intermediate (rac)-73. Aniline ( $r a c)$-72 was prepared from sulfonyl chloride $\mathbf{7 0}$ using chemistry discussed previously (vide supra). The pyridine nitrogen was quaternised using methyl iodide before the intermediate pyridinium ion was reduced using sodium borohydride to afford $(\boldsymbol{R})-\mathbf{5 5} . .^{50}$

Scheme 4. Synthesis of $(\boldsymbol{R})-55$.

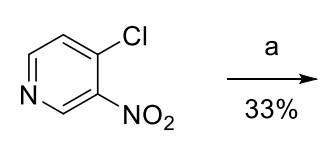

66

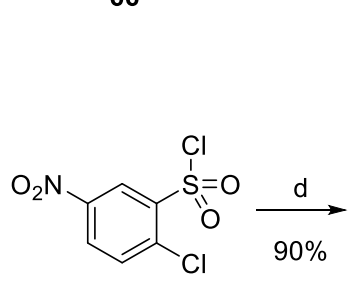

70

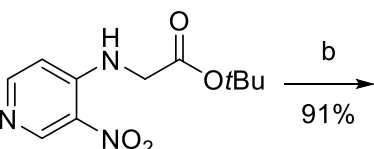

67

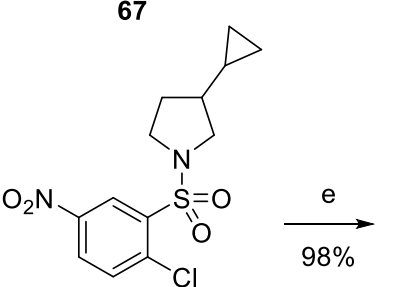

(rac)-71

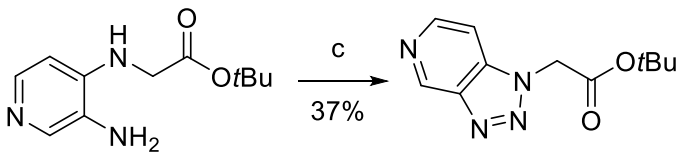

68

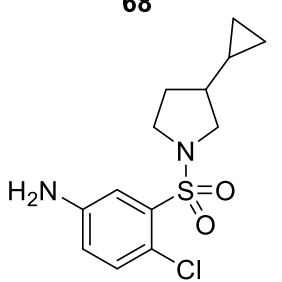

(rac)-72

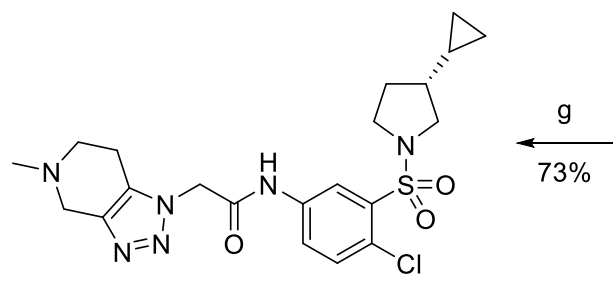

$(R)-55$
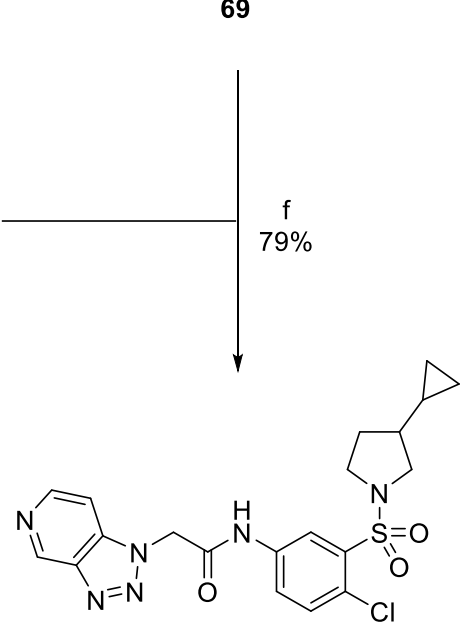

(rac)-73

Reagents and conditions: a) tert-butyl glycinate (1.1 eq.), TEA (1.0 eq.), EtOH, reflux, 6 h, 33\%; b) iron (5.0 eq.), $\mathrm{NH}_{4} \mathrm{Cl}$ (1.5 eq.), EtOH:water (3:1), $70{ }^{\circ} \mathrm{C}, 2 \mathrm{~h}, 91 \%$; c) $\mathrm{NaNO}_{2}$ (1.2 eq.), AcOH:water (1:1), $0{ }^{\circ} \mathrm{C}-80{ }^{\circ} \mathrm{C}, 37 \%$; d) 3-cyclopropylpyrrolidine (1.0 eq.), DIPEA (2.2 eq.), $\mathrm{CH}_{2} \mathrm{Cl}_{2}, 0{ }^{\circ} \mathrm{C}, 2 \mathrm{~h}, 90 \%$; e) iron (3.0 eq.), $\mathrm{NH}_{4} \mathrm{Cl}\left(1.5\right.$ eq.), 3:1 EtOH:water, $70{ }^{\circ} \mathrm{C}, 2 \mathrm{~h}, 98 \%$; f) $\mathrm{HCl}$ (4 $\mathrm{M}$ in dioxane, 8.3 eq.), $40{ }^{\circ} \mathrm{C}$, overnight then $\mathrm{HATU}$ (1.2 eq.), DIPEA (3.0 eq.), $\mathrm{CH}_{2} \mathrm{Cl}_{2}$, rt, $2 \mathrm{~h}, 79 \%$; g) $\mathrm{MeI}\left(1.0\right.$ eq.), $\mathrm{MeCN}, 80^{\circ} \mathrm{C}, 2 \mathrm{~h}$, then $\mathrm{NaBH}_{4}$ (2.2 eq.), 1:1 MeOH:water, rt, $73 \%$. 


\section{Profiling of the Lead compounds:}

Phenyl sulfonamides $(\boldsymbol{R})-\mathbf{5 4}$ and $(\boldsymbol{R})-\mathbf{5 5}$ had been identified for further profiling as the most potent and ATAD2 selective CECR2 analogues. Cellular target engagement was again demonstrated using a CECR2 nanoBRET assay. ${ }^{42}$ Both $(\boldsymbol{R})-54$ and $(\boldsymbol{R})-\mathbf{5 5}$ showed nanomolar activity $\left(\mathrm{pIC}_{50}=\right.$ 7.4 and 7.3 respectively). Their wider bromodomain selectivity was then investigated. Both $(\boldsymbol{R})-$ 54 and $(\boldsymbol{R})$-55 displayed excellent selectivity over BRD4 BD1 (>1300-fold) and BD2 (>500-fold). They were then initially submitted to DiscoverX's BROMOscan panel at a single $10 \mu \mathrm{M}$ concentration. This identified GCN5L2 and TAF1(2) as potential off-targets. Therefore, concentration-response curves were generated for these bromodomains along with CECR2. A TAF1(2) TR-FRET assay had previously been established in our laboratories and data was generated for both compounds. $(\boldsymbol{R})$-54 retained CECR2 potency in the DiscoverX assay $\left(\mathrm{pK}_{\mathrm{d}}=\right.$ 8.0) however, showed <30-fold selectivity over both GCN5L2 and TAF1(2). Interestingly, the TAF1(2) TR-FRET data showed 130-fold selectivity for CECR2, a marked discrepency between the 2 data sources (see Supporting Information). Encouragingly, $(\boldsymbol{R})$-55 showed an improved selectivity profile against both GCN5L2 (63-fold) and TAF1(2) (25-fold). The TR-FRET data generated also showed an increased window for CECR2 over TAF1(2) (50-fold). Due to the excellent selectivity profile of ( $\boldsymbol{R})$-55 (GSK232) against key off-target bromodomains and confirmed cellular target engagement, it was nominated as a chemical tool for the CECR2 bromodomain and was assessed in the full BROMOscan panel which is visualised on the phylogenetic tree (Fig 6). As identified throughout this work the closest off-targets were ATAD2 (79-fold selective), ATAD2B (63-fold selective), GCN5L2 (63-fold selective), TAF1(2) (25-fold selective), and TAF1L(2) (40-fold selective). Pleasingly $>100$-fold selectivity $\left(\mathrm{pK}_{\mathrm{d}}<6.1\right)$ was 
observed against all other bromodomains tested (for a full table of $\mathrm{K}_{\mathrm{d}} \mathrm{S}$ see Table S2, Supporting Information).

Table 10. Profiles of CECR2 tools $(\boldsymbol{R})-54$ and $(\boldsymbol{R})-\mathbf{5 5}$.

\begin{tabular}{|c|c|c|c|}
\hline & & $(R)-54$ & $\begin{array}{c}(\mathrm{GSK} 232) \\
(\boldsymbol{R})-\mathbf{5 5}\end{array}$ \\
\hline & $\mathrm{CR} 2 \mathrm{pIC}_{50}$ & $8.2(3)$ & $7.7(4)$ \\
\hline & E / LLE & $0.35 / 0.38$ & $0.33 / 0.36$ \\
\hline BRD4 B & $11 \mathrm{pIC}_{50}(\mathrm{n}) /$ Sel. & $4.9(2) / 2000 x$ & $4.6(4) / 1300 x$ \\
\hline BRD4 B & $2 \mathrm{pIC}_{50}(\mathrm{n}) /$ Sel. & $5.3 / 790 \mathrm{x}$ & $5.0(4) / 500 \mathrm{x}$ \\
\hline DiscoverX & CECR2 $\mathrm{pK}_{\mathrm{d}}$ & 8.0 & 8.1 \\
\hline BROMO & GCN5L2 pK d $_{\text {/ Sel. }}$ & $6.8 / 20 \mathrm{x}$ & $6.3 / 63 x$ \\
\hline -scan & TAF1(2) $\mathrm{pK}_{\mathrm{d}} /$ Sel. & $7.2 / 8 x$ & $6.7 / 25 x$ \\
\hline TAF1( & $\mathrm{pIC}_{50}(\mathrm{n}) /$ Sel. & $6.1(3) / 130 x$ & $6.0(3) / 50 \mathrm{x}$ \\
\hline CECR2 $\mathrm{r}$ & noBRET pIC $50(\mathrm{n})$ & 7.4(3) & $7.3(3)$ \\
\hline
\end{tabular}




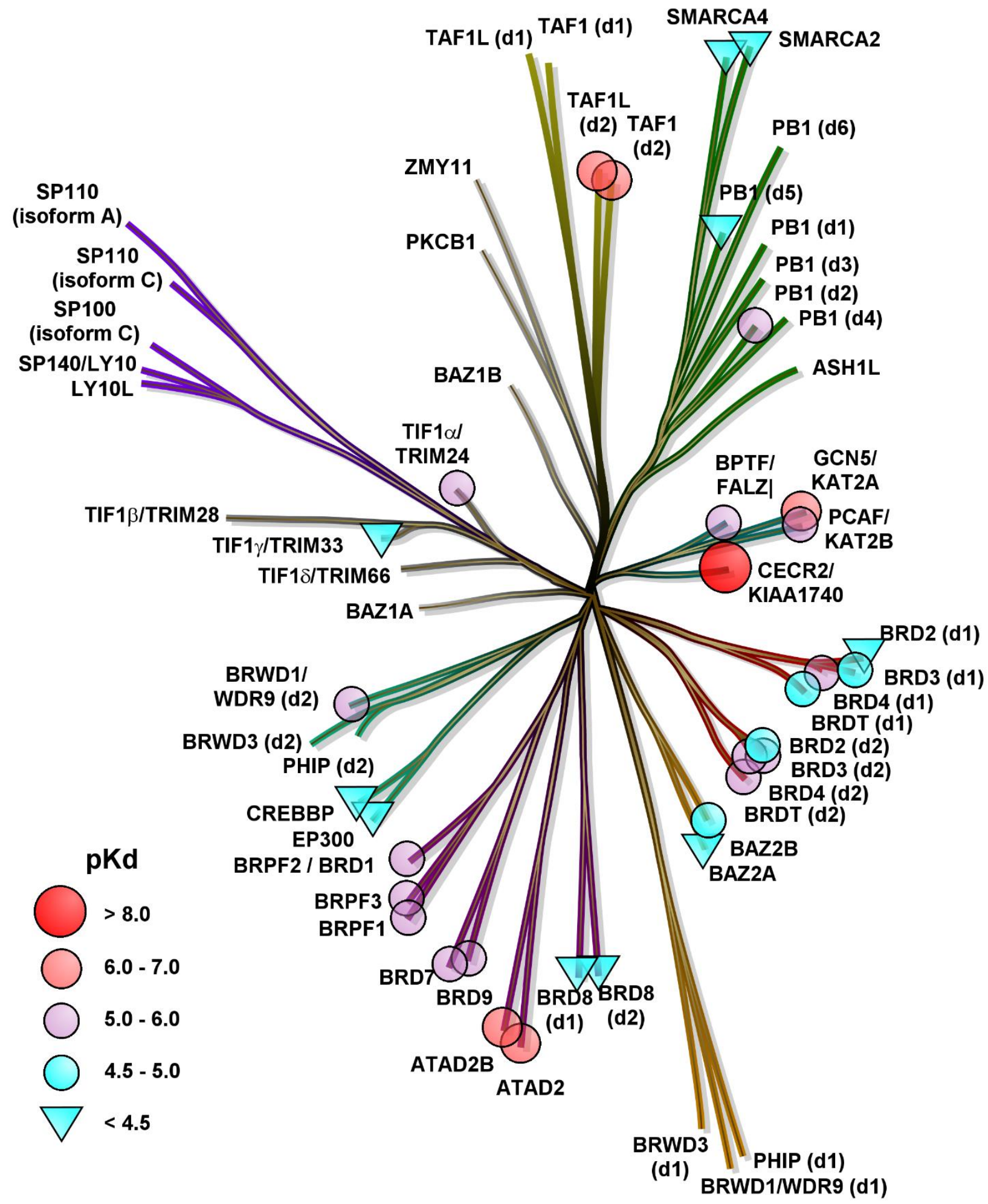

Fig. 6. DiscoverX's BROMOscan results of $(\boldsymbol{R})-\mathbf{5 5}$. 


\section{CONCLUSION}

In summary, we have optimised a series of phenyl sulfonamide bromodomain inhibitors, initially identified from a HTS against ATAD2, which displace the conserved water network from the KAc binding site. Optimisation of this template for ATAD2 potency/selectivity was achieved through an iterative medicinal chemistry approach, aided by crystallography, to deliver $(S, S)-32$ (GSK388) as a potent ATAD2 inhibitor with >200-fold selectivity over the BET family, which will be a valuable addition to the ATAD2 literature. Interestingly, $(\boldsymbol{S}, \boldsymbol{S})-\mathbf{3 2}$ not only inhibited ATAD2, where the stability of the water network is predicted to be amongst the least stable, but also CECR2, where the water network is predicted to be more stable. Differences in the RVF/WPF shelf regions of ATAD2 and CECR2 were then exploited to secure high CECR2 selectivity, culminating in ( $\boldsymbol{R})-55$ (GSK232). This was a highly potent ligand with >30-fold selectivity over all other bromodomains tested and >500-fold selectivity over the BET family. (R)-55 had an excellent physicochemical profile and was highly soluble. Cellular target engagement was demonstrated using a nanoBRET assay and as such $(\boldsymbol{R}) \mathbf{- 5 5}$ is a high quality chemical probe.

\section{EXPERIMENTAL SECTION}

\section{General Experimental}

Unless otherwise stated, all reactions were carried out under an atmosphere of nitrogen in heat or oven dried glassware and anhydrous solvent. Solvents and reagents were purchased from commercial suppliers and used as received. Reactions were monitored by thin layer chromatography (TLC) or liquid chromatography-mass spectrometry (LC-MS). TLC was carried out on glass or aluminium-backed 60 silica plates coated with $\mathrm{UV}_{254}$ fluorescent indicator. Spots were visualized using UV light (254 or $365 \mathrm{~nm}$ ) or alkaline $\mathrm{KMnO}_{4}$ solution, followed by gentle 
heating. LCMS analysis was carried out on a Waters Acquity UPLC instrument equipped with a BEH column (50 mm x $2.1 \mathrm{~mm}, 1.7 \mu \mathrm{m}$ packing diameter) and Waters micromass ZQ MS using alternate-scan positive and negative electrospray. Analytes were detected as a summed UV wavelength of $210-350 \mathrm{~nm}$. Flash column chromatography was carried out using Biotage SP4 or Isolera One apparatus with SNAP silica cartridges. Mass directed automatic purification (MDAP) was carried out using a Waters ZQ MS using alternate-scan positive and negative electrospray and a summed UV wavelength of $210-350 \mathrm{~nm}$. NMR spectra were recorded at ambient temperature (unless otherwise stated) using standard pulse methods on any of the following spectrometers and signal frequencies: Bruker AV-400 $\left({ }^{1} \mathrm{H}=400 \mathrm{MHz},{ }^{13} \mathrm{C}=101 \mathrm{MHz},\right)$, Bruker AV-600 $\left({ }^{1} \mathrm{H}=600\right.$ $\mathrm{MHz},{ }^{13} \mathrm{C}=150 \mathrm{MHz}$,), Bruker DPX-250 spectrometer at $250 \mathrm{MHz}$, Varian INOVA spectrometer at $300 \mathrm{MHz}$. Chemical shifts are referenced to trimethylsilane (TMS) or the residual solvent peak, and are reported in ppm. Coupling constants are quoted to the nearest $0.1 \mathrm{~Hz}$ and multiplicities are given by the following abbreviations and combinations thereof: $\mathrm{s}$ (singlet), $\delta$ (doublet), $\mathrm{t}$ (triplet), q (quartet), quin (quintet), sxt (sextet), m (multiplet), br. (broad). IR spectra were obtained on a Perkin Elmer Spectrum 1 machine. Optical rotation of chiral products was measured using a Jasco P1030 polarimeter. Melting point analysis was carried out using a Stuart SMP40 melting point apparatus. Liquid chromatography high resolution mass spectra (HRMS) were recorded on a Micromass Q-Tof Ultima hybrid quadrupole time-of-flight mass spectrometer, with analytes separated on an Agilent 1100 Liquid Chromatograph equipped with a Phenomenex Luna C18(2) reversed phase column (100 mm x $2.1 \mathrm{~mm}, 3 \mu \mathrm{m}$ packing diameter). Purity of synthesized compounds was determined by LCMS analysis. All compounds for biological testing were $>95 \%$ pure.

\section{Synthesis of $(S, S)-32$ :}


(S)-1-((2-Bromo-5-nitrophenyl)sulfonyl)-3-methylpyrrolidine ((S)-57): 2-Bromo-5-nitrobenzene1-sulfonyl chloride 56 (1.70 g, $5.66 \mathrm{mmol})$ was taken up in $\mathrm{CH}_{2} \mathrm{Cl}_{2}(5 \mathrm{~mL})$ under nitrogen and cooled in an ice bath. DIPEA $(2.17 \mathrm{~mL}, 12.45 \mathrm{mmol})$ was added and the reaction stirred for $5 \mathrm{~min}$ before $(S)$-3-methylpyrrolidine hydrochloride $(0.69 \mathrm{~g}, 5.66 \mathrm{mmol})$ was added. The reaction was stirred for $1 \mathrm{~h}$ before warming to $\mathrm{rt}$. The reaction mixture was quenched with sat. aq. $\mathrm{NaHCO}_{3}(10$ $\mathrm{mL})$ and extracted with $\mathrm{CH}_{2} \mathrm{Cl}_{2}(2 \times 20 \mathrm{~mL})$. The combined organics were washed with $2 \mathrm{M} \mathrm{HCl}$ aq. (10 mL), filtered through a hydrophobic frit and concentrated in vacuo to give the crude product. The crude product was purified by silica chromatography, eluting with $0-40 \%$ EtOAc/cyclohexane. The pure fractions were concentrated in vacuo to afford (S)-1-((2-bromo-5nitrophenyl)sulfonyl)-3-methylpyrrolidine $(\boldsymbol{S})-57(1.77 \mathrm{~g}, 5.08 \mathrm{mmol}, 90 \%$ yield $)$ as a yellow solid. LCMS (Formic, $\left.\mathrm{ES}^{+}\right) \mathrm{t}_{\mathrm{R}}=1.17 \mathrm{~min}, \mathrm{~m} / z=349.1,351.1 ;{ }^{1} \mathrm{H} \mathrm{NMR}\left(\mathrm{CDCl}_{3}-d, 400 \mathrm{MHz}\right): \delta$ (ppm) $8.89(\mathrm{~d}, J=2.7 \mathrm{~Hz}, 1 \mathrm{H}), 8.21(\mathrm{dd}, J=8.8,2.7 \mathrm{~Hz}, 1 \mathrm{H}), 7.95(\mathrm{~d}, J=8.8 \mathrm{~Hz}, 1 \mathrm{H}), 3.56-3.67(\mathrm{~m}$, 2H), 3.45 (ddd, $J=9.5,8.6,7.1 \mathrm{~Hz}, 1 \mathrm{H}), 2.98(\mathrm{dd}, J=9.4,7.9 \mathrm{~Hz}, 1 \mathrm{H}), 2.28-2.43(\mathrm{~m}, 1 \mathrm{H}), 2.09$ (dtd, $J=12.7,6.6,3.9 \mathrm{~Hz}, 1 \mathrm{H}), 1.53-1.67(\mathrm{~m}, 1 \mathrm{H}), 1.07(\mathrm{~d}, J=6.6 \mathrm{~Hz}, 3 \mathrm{H}) ;{ }^{13} \mathrm{C} \mathrm{NMR}\left(\mathrm{CDCl}_{3}-d, 101\right.$ MHz): $\delta$ (ppm) 146.8, 141.2, 127.7, 127.2, 126.6, 126.1, 59.6, 54.8, 47.9, 33.7, 17.4; IR $v_{\max }\left(\mathrm{cm}^{-}\right.$ 1) $3000,1595,1528,1331,1153,1125,1057,1022,880,842,774,739,697,670$.

(S)-4-Bromo-3-((3-methylpyrrolidin-1-yl)sulfonyl)aniline $\quad((S)-58): \quad(S)-1-((2-B r o m o-5-$ nitrophenyl)sulfonyl)-3-methylpyrrolidine (S)-57 (2.92 g, $8.36 \mathrm{mmol})$, ammonium chloride (0.67 $\mathrm{g}, 12.54 \mathrm{mmol})$ and iron $(2.36 \mathrm{~g}, 41.8 \mathrm{mmol})$ were dissolved in a 3:1 mixture of EtOH (20 mL) and water $(7 \mathrm{~mL})$. The resulting solution was heated to $70{ }^{\circ} \mathrm{C}$ for $2 \mathrm{~h}$. The reaction was allowed to cool then filtered through a plug of Celite, washing with $\mathrm{MeOH}(50 \mathrm{~mL})$. The resulting solution was concentrated in vacuo and then partitioned with sat. aq. $\mathrm{NaHCO}_{3}(20 \mathrm{~mL})$ and $\mathrm{CH}_{2} \mathrm{Cl}_{2}(20$ $\mathrm{mL})$. The layers were separated and the aq. extracted with $\mathrm{CH}_{2} \mathrm{Cl}_{2}(2 \times 20 \mathrm{~mL})$. The combined 
organics were passed through a hydrophobic frit and concentrated in vacuo to afford $(S)$-4-bromo3-((3-methylpyrrolidin-1-yl)sulfonyl)aniline $(\boldsymbol{S})-58$ (2.62 g, $8.21 \mathrm{mmol}, 98 \%$ yield) as an orange gum. LCMS (formic, $\mathrm{ES}^{+}$) $\mathrm{t}_{\mathrm{R}}=1.00 \mathrm{~min}, \mathrm{~m} / \mathrm{z}=319.1$, 321.1; $\mathrm{HRMS}\left(\mathrm{C}_{11} \mathrm{H}_{15} \mathrm{BrN}_{2} \mathrm{O}_{2} \mathrm{~S}\right):[\mathrm{M}+\mathrm{H}]^{+}$ calculated 319.0116, found 319.0114; ${ }^{1} \mathrm{H}$ NMR $\left(\mathrm{CDCl}_{3}-d, 400 \mathrm{MHz}\right): \delta(\mathrm{ppm}) 7.41-7.49(\mathrm{~m}, 2 \mathrm{H})$, 6.67 (dd, $J=8.4,2.8 \mathrm{~Hz}, 1 \mathrm{H}), 3.92$ (br. s., $2 \mathrm{H}), 3.51-3.62(\mathrm{~m}, 2 \mathrm{H}), 3.33-3.44$ (m, J=9.5, 8.6, 7.1 Hz, $1 \mathrm{H}), 2.88-2.96(\mathrm{~m}, 1 \mathrm{H}), 2.26-2.38(\mathrm{~m}, J=14.9,8.5,6.8,6.8 \mathrm{~Hz}, 1 \mathrm{H}), 1.99-2.09(\mathrm{~m}, 1 \mathrm{H}), 1.50-1.57$ $(\mathrm{m}, 1 \mathrm{H}), 1.05(\mathrm{~d}, J=6.6 \mathrm{~Hz}, 3 \mathrm{H}) ;{ }^{13} \mathrm{C} \mathrm{NMR}\left(\mathrm{CDCl}_{3}-d, 101 \mathrm{MHz}\right): \delta(\mathrm{ppm}) 146.0,138.8,136.0$ 119.4, 118.4, 106.8, 54.4, 47.5, 33.8, 33.6, 17.5; IR $v_{\max }\left(\mathrm{cm}^{-1}\right) 3467,3371,1591,1468,1328$, 1142, 584.

(S,S)-N-(4-Bromo-3-(((S)-3-methylpyrrolidin-1-yl)sulfonyl)phenyl)-2-((S)-4-cyclopropyl-4methyl-2,5-dioxoimidazolidin-1-yl)acetamide ((S,S)-32): (S)-4-Bromo-3-((3-methylpyrrolidin-1yl)sulfonyl)aniline $(\boldsymbol{S})-58(265 \mathrm{mg}, 0.830 \mathrm{mmol})$ was taken up in $\mathrm{CH}_{2} \mathrm{Cl}_{2}$ (3 mL). (rac)-2-(4Cyclopropyl-4-methyl-2,5-dioxoimidazolidin-1-yl)acetic acid (194 mg, $0.913 \mathrm{mmol}$ ) and DIPEA (0.435 mL, $2.490 \mathrm{mmol})$ were added. T3P (50\% w/w in EtOAc, $1.438 \mathrm{~mL}, 0.830 \mathrm{mmol})$ was then added and the reaction stirred at $\mathrm{rt}$ for $2 \mathrm{~h}$. The reaction was concentrated in vacuo and the residue was partitioned between $\mathrm{CH}_{2} \mathrm{Cl}_{2}$ and sat. aq. $\mathrm{NaHCO}_{3}(15 \mathrm{~mL}$ each). The aqueous layer was reextracted with $\mathrm{CH}_{2} \mathrm{Cl}_{2}(15 \mathrm{~mL})$ and the combined organics eluted through a hydrophobic frit then concentrated in vacuo to afford the crude product. The crude product was purified by silica chromatography eluting with 5-50\% (3:1 EtOAc:EtOH)/cyclohexane. The pure fractions were concentrated in vacuo to give the $N$-(4-bromo-3-(((S)-3-methylpyrrolidin-1-yl)sulfonyl)phenyl)2-(4-cyclopropyl-4-methyl-2,5-diox oimidazolidin-1-yl)acetamide (326 mg, $0.604 \mathrm{mmol}, 73 \%$ ) as a (1:1) mixture of diastereomers. The pure fractions were concentrated in vacuo to afford the racemic product. The racemate was was dissolved in $\mathrm{EtOH}(5 \mathrm{~mL})$ and injected onto the column 
(column: $250 \mathrm{~mm}$ x $20 \mathrm{~mm}$ Chiralcpak AD-H, $5 \mu \mathrm{m})$, eluting with $20 \%(\mathrm{EtOH}+0.2 \%$ isopropylamine $) /($ Heptane $+0.2 \%$ isopropylamine $)$, flow rate $=42.5 \mathrm{~mL} \mathrm{~min}{ }^{-1}$, detection wavelength $280 \mathrm{~nm}$. The pure fractions from peak 2 were concentrated in vacuo to afford $\mathrm{N}$-(4Bromo-3-(((S)-3-methylpyrrolidin-1-yl)sulfonyl)phenyl)-2-((S)-4-cyclopropyl-4-methyl-2,5dioxoimidazolidin-1-yl)acetamide (129 mg, $0.238 \mathrm{mmol}, 29 \%)(\boldsymbol{S}, \mathbf{S})-32$ as a cream solid. LCMS $\left(\right.$ Formic, $\left.\mathrm{ES}^{+}\right) \mathrm{t}_{\mathrm{R}}=1.04 \mathrm{~min}, \mathrm{~m} / z=513.2,515.2(100 \%$ pure $)$; $\mathrm{HRMS}\left(\mathrm{C}_{20} \mathrm{H}_{25} \mathrm{BrN}_{4} \mathrm{O}_{5} \mathrm{~S}\right):[\mathrm{M}+\mathrm{H}]^{+}$ calculated 513.0807, found 513.0804; ${ }^{1} \mathrm{H}$ NMR (DMSO- $d_{6}, 400 \mathrm{MHz}$ ): $\delta(\mathrm{ppm}) 10.70(\mathrm{~s}, 1 \mathrm{H})$, $8.28(\mathrm{~d}, J=2.7 \mathrm{~Hz}, 1 \mathrm{H}), 8.16(\mathrm{~s}, 1 \mathrm{H}), 7.80(\mathrm{~d}, J=8.7,1 \mathrm{H}), 7.70(\mathrm{dd}, J=8.7,2.6 \mathrm{~Hz}, 1 \mathrm{H}), 4.19$ (s, 2H), 3.40-3.52 (m, 2H), 3.31-3.35 (m, 1H), $2.84(\mathrm{dd}, J=9.4,7.7 \mathrm{~Hz}, 1 \mathrm{H}), 2.22-2.35(\mathrm{~m}, 1 \mathrm{H}), 1.95-$ $2.07(\mathrm{~m}, 1 \mathrm{H}), 1.52(\mathrm{dq}, J=12.3,8.3 \mathrm{~Hz}, 1 \mathrm{H}), 1.40(\mathrm{~s}, 3 \mathrm{H}), 1.10-1.20(\mathrm{~m}, 1 \mathrm{H}), 0.93-1.01(\mathrm{~m}, 3 \mathrm{H})$ 0.40-0.49 (m, 2H), 0.26-0.39 (m, 2H); ${ }^{13} \mathrm{C}$ NMR (DMSO- $\left.d_{6}, 101 \mathrm{MHz}\right): \delta(\mathrm{ppm}) 176.8,165.8$, 156.0, 138.8, 138.8, 136.7, 124.2, 121.5, 112.6, 61.0, 54.7, 47.9, 41.1, 33.6, 33.4, 23.6, 17.6, 17.4, 0.9, 0.4; IR $v_{\max }\left(\mathrm{cm}^{-1}\right) 3295,1712,1601,1536,1457,1307$; m.p. $218.8-220.5^{\circ} \mathrm{C}$; Chiral LC: $4.6 \mathrm{~mm} \times 250 \mathrm{~mm}$ Chiralpak AD-H column, $20 \%(\mathrm{EtOH}+0.2 \%$ isopropylamine $) /($ Heptane + $0.2 \%$ isopropylamine), $\mathrm{t}_{\mathrm{R}}=23.301 \mathrm{~min} ;$ er 95:1.

\section{Synthesis of $(R)-55$ :}

(rac)-1-((2-Chloro-5-nitrophenyl)sulfonyl)-3-cyclopropylpyrrolidine $\quad((\boldsymbol{r a c})-71): \quad 2-C h l o r o-5-$ nitrobenzenesulfonyl chloride $70(1.10 \mathrm{~g}, 4.30 \mathrm{mmol})$ was taken up in $\mathrm{CH}_{2} \mathrm{Cl}_{2}(50 \mathrm{~mL})$ under nitrogen and cooled to $0{ }^{\circ} \mathrm{C}$. DIPEA $(1.65 \mathrm{~mL}, 9.45 \mathrm{mmol})$ was added and the reaction stirred for $5 \mathrm{~min}$ before ( $\mathrm{rac})$-3-cyclopropylpyrrolidine $(0.48 \mathrm{~g}, 4.30 \mathrm{mmol})$ was added. The reaction was stirred at $0{ }^{\circ} \mathrm{C}$ for $2 \mathrm{~h}$. The reaction mixture was quenched with sat. $\mathrm{NaHCO}_{3}(50 \mathrm{~mL})$ and extracted with $\mathrm{CH}_{2} \mathrm{Cl}_{2}(2 \times 50 \mathrm{~mL})$. The combined organics were filtered through a hydrophobic frit and concentrated in vacuo to give the crude product. The crude product was purified by silica 
chromatography, eluting with $0-40 \%$ cyclohexane/EtOAc. The pure fractions were concentrated in vacuo to afford (rac)-1-((2-chloro-5-nitrophenyl)sulfonyl)-3-cyclopropylpyrrolidine (rac)-71 $\left(1.28 \mathrm{~g}, 3.87 \mathrm{mmol}, 90 \%\right.$ yield) as a yellow gum. LCMS (formic, $\mathrm{ES}^{+}$) $\mathrm{t}_{\mathrm{R}}=1.23 \mathrm{~min}, \mathrm{~m} / \mathrm{z}=331.2$; HRMS $\left(\mathrm{C}_{13} \mathrm{H}_{15} \mathrm{ClN}_{2} \mathrm{O}_{4} \mathrm{~S}\right):[\mathrm{M}+\mathrm{H}]^{+}$calculated 331.0519, found 331.0510; ${ }^{1} \mathrm{H}$ NMR $\left(\mathrm{CDCl}_{3}-d, 400\right.$ MHz): $\delta$ (ppm) $8.92(\mathrm{~d}, J=2.7 \mathrm{~Hz}, 1 \mathrm{H}), 8.33(\mathrm{dd}, J=8.8,2.7 \mathrm{~Hz}, 1 \mathrm{H}), 7.71(\mathrm{~d}, J=8.8 \mathrm{~Hz}, 1 \mathrm{H}), 3.58-$ $3.69(\mathrm{~m}, 2 \mathrm{H}), 3.45(\mathrm{ddd}, J=9.7,8.3,7.2 \mathrm{~Hz}, 1 \mathrm{H}), 3.21(\mathrm{dd}, J=9.5,7.8 \mathrm{~Hz}, 1 \mathrm{H}), 2.03-2.15(\mathrm{~m}, 1 \mathrm{H})$, $1.80(\mathrm{dq}, J=12.5,8.3 \mathrm{~Hz}, 1 \mathrm{H}), 1.60-1.69(\mathrm{~m}, 1 \mathrm{H}), 0.63-0.76(\mathrm{~m}, 1 \mathrm{H}), 0.43-0.55(\mathrm{~m}, 2 \mathrm{H}), 0.08-$ 0.22 (m, 2H); ${ }^{13} \mathrm{C}$ NMR $\left(\mathrm{CDCl}_{3}-d, 101 \mathrm{MHz}\right): \delta(\mathrm{ppm}) 146.2,139.4,139.0,133.2,127.4,126.7$, 52.9, 47.8, 44.4, 31.5, 13.0, 3.7, 3.4; IR $v_{\max }\left(\mathrm{cm}^{-1}\right) 3098,1601,1524,1344,1162,884$.

(rac)-4-Chloro-3-((3-cyclopropylpyrrolidin-1-yl)sulfonyl)aniline ((rac)-72): (rac)-1-((2-Chloro5-nitrophenyl)sulfonyl)-3-cyclopropylpyrrolidine ( $\mathbf{r a c}$ )-71 (1.25 g, $3.78 \mathrm{mmol})$, ammonium chloride $(0.30 \mathrm{~g}, 5.67 \mathrm{mmol})$ and iron $(0.63 \mathrm{~g}, 11.34 \mathrm{mmol})$ were dissolved in $\mathrm{EtOH}(5.0 \mathrm{~mL})$ and water $(1.7 \mathrm{~mL})$. The resulting solution was heated to $70{ }^{\circ} \mathrm{C}$ for $2 \mathrm{~h}$. The reaction was allowed to cool then filtered through a plug of Celite, washing with $\mathrm{MeOH}(20 \mathrm{~mL})$. The resulting solution was concentrated in vacuo and then partitioned between sat. aq. $\mathrm{NaHCO}_{3}(20 \mathrm{~mL})$ and $\mathrm{CH}_{2} \mathrm{Cl}_{2}(20$ $\mathrm{mL})$. The layers were separated and the aq. layer extracted with $\mathrm{CH}_{2} \mathrm{Cl}_{2}(2 \times 20 \mathrm{~mL})$. The combined organics were passed through a hydrophobic frit and concentrated in vacuo to afford (rac)-4chloro-3-((3-cyclopropylpyrrolidin-1-yl)sulfonyl)aniline ( $r a c)-72$ (1.11 g, 3.69 mmol, 98\% yield) as a yellow gum. LCMS (formic, $\left.\mathrm{ES}^{+}\right) \mathrm{t}_{\mathrm{R}}=1.07 \mathrm{~min}, \mathrm{~m} / z=301.1 ; \mathrm{HRMS}\left(\mathrm{C}_{13} \mathrm{H}_{17} \mathrm{ClN}_{2} \mathrm{O}_{2} \mathrm{~S}\right)$ : $[\mathrm{M}+\mathrm{H}]^{+}$calculated 301.0778, found 301.0771; ${ }^{1} \mathrm{H}$ NMR $\left(\mathrm{CDCl}_{3}-d, 400 \mathrm{MHz}\right): \delta(\mathrm{ppm}) 7.41(\mathrm{~d}$, $J=2.7 \mathrm{~Hz}, 1 \mathrm{H}), 7.26$ (d, $J=8.5 \mathrm{~Hz}, 1 \mathrm{H}), 6.75$ (dd, $J=8.5,2.7 \mathrm{~Hz}, 1 \mathrm{H}), 3.91$ (br. s., $2 \mathrm{H}), 3.53-3.63$ (m, 2H), 3.39 (ddd, J=9.5, 8.3, 7.1 Hz, 1H), $3.15(\mathrm{dd}, J=9.5,7.7 \mathrm{~Hz}, 1 \mathrm{H}), 1.98-2.09(\mathrm{~m}, 1 \mathrm{H}), 1.74$ (dq, $J=12.3,8.4 \mathrm{~Hz}, 1 \mathrm{H}), 1.56-1.61(\mathrm{~m}, 1 \mathrm{H}), 0.60-0.74(\mathrm{~m}, 1 \mathrm{H}), 0.41-0.52(\mathrm{~m}, 2 \mathrm{H}), 0.08-0.18$ 
$(\mathrm{m}, 2 \mathrm{H}) ;{ }^{13} \mathrm{C} \mathrm{NMR}\left(\mathrm{CDCl}_{3}-d, 101 \mathrm{MHz}\right): \delta(\mathrm{ppm}) 145.4,137.1,132.5,120.1,119.2,118.0,52.5$, 47.4, 44.3, 31.5, 13.1, 3.6, 3.3; IR $v_{\max }\left(\mathrm{cm}^{-1}\right) 3375,1596,1468,1323,1159,590$.

(rac)-2-(1H-[1,2,3]Triazolo[4,5-c]pyridin-1-yl)-N-(4-chloro-3-((3-cyclopropylpyrrolidin-1-yl) sulfonyl)phenyl)acetamide ((rac)-73): tert-Butyl 2-(1H-[1,2,3]triazolo[4,5-c]pyridin-1-yl)acetate 69 (187 mg, $0.798 \mathrm{mmol})$ was dissolved in $\mathrm{HCl}(4 \mathrm{M}$ in dioxane, $1.66 \mathrm{~mL}, 6.65 \mathrm{mmol})$ and stirred at $\mathrm{rt}$ for $16 \mathrm{~h}$. The reaction mixture was concentrated in vacuo to afford the crude acid. (rac)-4Chloro-3-((3-cyclopropylpyrrolidin-1-yl)sulfonyl)aniline (rac)-73 (200 mg, $0.665 \mathrm{mmol})$, and HATU (303 mg, $0.798 \mathrm{mmol}$ ) were added and the mixture dissolved in $\mathrm{CH}_{2} \mathrm{Cl}_{2}$ (10 mL). DIPEA $(0.348 \mathrm{~mL}, 1.995 \mathrm{mmol})$ was added and the resulting solution was stirred at $\mathrm{rt}$ for $2 \mathrm{~h}$. The reaction was quenched with sat. aq. $\mathrm{NaHCO}_{3}(10 \mathrm{~mL})$ and extracted with $\mathrm{CH}_{2} \mathrm{Cl}_{2}(3 \times 10 \mathrm{~mL})$. The combined organics were passed through a hydrophobic frit and concentrated in vacuo to afford the crude product. The crude product was purified by silica chromatography, eluting with $0-100 \%$ EtOAc/cyclohexane. The pure fractions were concentrated in vacuo to afford (rac)-2-(1H[1,2,3]triazolo[4,5-c]pyridin-1-yl)-N-(4-chloro-3-((3-cyclopropylpyrrolidin-1-

yl)sulfonyl)phenyl)acetamide ( (ac)-73 (241 $\mathrm{mg}, 0.523 \mathrm{mmol}, 79 \%$ yield) as a cream solid. LCMS (formic, $\left.\mathrm{ES}^{+}\right) \mathrm{t}_{\mathrm{R}}=0.98 \mathrm{~min}, \mathrm{~m} / z=461.3 ; \mathrm{HRMS}\left(\mathrm{C}_{20} \mathrm{H}_{21} \mathrm{ClN}_{6} \mathrm{O}_{3} \mathrm{~S}\right):[\mathrm{M}+\mathrm{H}]^{+}$calculated 461.1163, found $461.1161 ;{ }^{1} \mathrm{H}^{1} \mathrm{H}$ NMR $\left(\mathrm{CDCl}_{3}-d, 400 \mathrm{MHz}\right): \delta(\mathrm{ppm}) 9.45(\mathrm{~d}, J=1.1 \mathrm{~Hz}, 1 \mathrm{H}), 9.16(\mathrm{~s}, 1 \mathrm{H})$, $8.58(\mathrm{~d}, J=6.0 \mathrm{~Hz}, 1 \mathrm{H}), 8.25(\mathrm{~d}, J=2.7 \mathrm{~Hz}, 1 \mathrm{H}), 7.82(\mathrm{dd}, J=8.8,2.7 \mathrm{~Hz}, 1 \mathrm{H}), 7.65(\mathrm{dd}, J=6.0,1.1$ $\mathrm{Hz}, 1 \mathrm{H}), 7.43(\mathrm{~d}, J=8.8 \mathrm{~Hz}, 1 \mathrm{H}), 5.67(\mathrm{~s}, 2 \mathrm{H}), 3.51-3.58(\mathrm{~m}, 2 \mathrm{H}), 3.30-3.39(\mathrm{~m}, 1 \mathrm{H}), 3.12(\mathrm{dd}$, $J=9.7,7.7 \mathrm{~Hz}, 1 \mathrm{H}), 1.97-2.06(\mathrm{~m}, 1 \mathrm{H}), 1.73(\mathrm{dd}, J=12.5,8.6 \mathrm{~Hz}, 1 \mathrm{H}), 1.51-1.63(\mathrm{~m}, 1 \mathrm{H}), 0.55-$ $0.67(\mathrm{~m}, 1 \mathrm{H}), 0.37-0.48(\mathrm{~m}, 2 \mathrm{H}), 0.05-0.12(\mathrm{~m}, 2 \mathrm{H}) ; \mathrm{m} . \mathrm{p} .63 .7-68.8{ }^{\circ} \mathrm{C} ; \mathrm{IR} v_{\max }\left(\mathrm{cm}^{-1}\right) 3008$ $1590,1465,1156,839,556$. 
(rac)-N-(4-Chloro-3-((3-cyclopropylpyrrolidin-1-yl)sulfonyl)phenyl)-2-(5-methyl-4,5,6,7-

tetrahydro-1H-[1,2,3]triazolo[4,5-c]pyridin-1-yl)acetamide ((rac)-55): Iodomethane $(0.16 \mathrm{~mL}$, $2.169 \mathrm{mmol})$ was added to $(\mathrm{rac})-2-(1 H-[1,2,3]$ triazolo[4,5-c]pyridin-1-yl)- $N$-(4-chloro-3-((3cyclopropylpyrrolidin-1-yl)sulfonyl)phenyl)acetamide ( $\mathbf{r a c})-73$ (1.00 g, $2.169 \mathrm{mmol})$ in $\mathrm{MeCN}$ $(20 \mathrm{~mL})$ at $\mathrm{rt}$ under air. The resulting solution was refluxed at $80{ }^{\circ} \mathrm{C}$ for $2 \mathrm{~h}$. The reaction was allowed to cool and concentrated in vacuo to afford the methyl pyridinium intermediate. The residue was dissolved in $\mathrm{MeOH}(10 \mathrm{~mL})$ and water $(10 \mathrm{~mL})$, before $\mathrm{NaBH}_{4}(0.18 \mathrm{~g}, 4.77 \mathrm{mmol})$ was added and the resulting solution stirred at $\mathrm{rt}$ for $30 \mathrm{~min}$. The reaction was quenched with water (20 mL) and extracted with $\mathrm{CH}_{2} \mathrm{Cl}_{2}(3 \times 20 \mathrm{~mL})$. The combined organics were passed through a hydrophobic frit and concentrated in vacuo to afford (rac)- $N$-(4-chloro-3-((3cyclopropylpyrrolidin-1-yl)sulfonyl)phenyl)-2-(5-methyl-4,5,6,7-tetrahydro- $1 H$-[1,2,3]triazol o[4,5-c]pyridin-1-yl)acetamide (rac)-55 (762 mg, $1.591 \mathrm{mmol}, 73 \%$ yield) as a white solid. LCMS $\left(\right.$ formic, $\left.\mathrm{ES}^{+}\right) \mathrm{t}_{\mathrm{R}}=0.68 \mathrm{~min}, \mathrm{~m} / \mathrm{z}=479.3 ; \mathrm{HRMS}\left(\mathrm{C}_{21} \mathrm{H}_{27} \mathrm{ClN}_{6} \mathrm{O}_{3} \mathrm{~S}\right)$ : $[\mathrm{M}+\mathrm{H}]^{+}$calculated 479.1632, found 479.1629; ${ }^{1} \mathrm{H}$ NMR $\left(\mathrm{CDCl}_{3}-d, 400 \mathrm{MHz}\right): d(\mathrm{ppm}) 8.98(\mathrm{~s}, 1 \mathrm{H}), 8.13(\mathrm{~d}, J=2.7 \mathrm{~Hz}, 1 \mathrm{H})$, $7.91(\mathrm{dd}, J=8.8,2.7 \mathrm{~Hz}, 1 \mathrm{H}), 7.46(\mathrm{~d}, J=8.8 \mathrm{~Hz}, 1 \mathrm{H}), 5.16(\mathrm{~s}, 2 \mathrm{H}), 3.70(\mathrm{~s}, 2 \mathrm{H}), 3.53-3.62(\mathrm{~m}, 2 \mathrm{H})$, 3.39 (ddd, $J=9.5,8.3,7.2 \mathrm{~Hz}, 1 \mathrm{H}), 3.15$ (dd, $J=9.5,7.8 \mathrm{~Hz}, 1 \mathrm{H}), 2.80-2.89(\mathrm{~m}, 4 \mathrm{H}), 2.56$ (s, 3H), $1.99-2.10(\mathrm{~m}, 1 \mathrm{H}), 1.76(\mathrm{dq}, J=12.2,8.4 \mathrm{~Hz}, 1 \mathrm{H}), 1.56-1.66(\mathrm{~m}, 1 \mathrm{H}), 0.60-0.71$ (m, 1H), 0.41$0.52(\mathrm{~m}, 2 \mathrm{H}), 0.09-0.18(\mathrm{~m}, 2 \mathrm{H}) ;{ }^{13} \mathrm{C} \mathrm{NMR}\left(\mathrm{CDCl}_{3}-d, 101 \mathrm{MHz}\right): \delta(\mathrm{ppm}) 163.6,143.0,137.3$, 136.1, 132.6, 132.2, 127.3, 124.7, 123.1, 77.2, 52.7, 51.4, 51.4, 47.6, 45.1, 44.3, 31.4, 20.6, 13.0, 3.7, 3.3; m.p. $91.8-97.8^{\circ} \mathrm{C}$; IR $v_{\max }\left(\mathrm{cm}^{-1}\right) 2950,1705,1535,1464,1157,591$.

(R)-N-(4-Chloro-3-((3-cyclopropylpyrrolidin-1-yl)sulfonyl)phenyl)-2-(5-methyl-4,5,6,7-

tetrahydro-1H-[1,2,3]triazolo[4,5-c]pyridin-1-yl)acetamide $((\boldsymbol{R})-55)$ and $(S)-N$-(4-chloro-3-((3cyclopropylpyrrolidin-1-yl)sulfonyl)phenyl)-2-(5-methyl-4,5,6,7-tetrahydro- $1 H$ - 
$[1,2,3]$ triazolo[4,5-c]pyridin-1-yl)acetamide

cyclopropylpyrrolidin-1-yl)sulfonyl)phenyl)-2-(5
$((S)-55)$ :

(rac)-N-(4-Chloro-3-((3-

-methyl-4,5,6,7-tetra hydro- $1 \mathrm{H}$ -

$[1,2,3]$ triazolo[4,5-c]pyridin-1-yl)acetamide (rac)-55 was dissolved in EtOH (1 mL) and injected onto the column (column: $250 \mathrm{~mm} \times 20 \mathrm{~mm}$ Chiralpak IG, $5 \mu \mathrm{m}$ ), eluting with $50 \%$ (EtOH $+0.2 \%$ isopropylamine)/(heptane $+0.2 \%$ isopropylamine), flow rate $=15 \mathrm{~mL} \mathrm{~min}^{-1}$, detection wavelength $215 \mathrm{~nm}$. The pure fractions from peak 1 were concentrated in vacuo to afford $\left(S^{*}\right)-N$-(4-chloro-3((3-cyclopropylpyrrolidin-1-yl)sulfonyl)phenyl)-2-(5-methyl-4,5,6,7-tetrahydro-1 $H$-[1,2,3]triazol o[4,5-c]pyridin-1-yl) acetamide $(\boldsymbol{R}) \mathbf{- 5 5}(16 \mathrm{mg}, 0.033 \mathrm{mmol})$ as a white solid and the pure fractions from peak 2 were concentrated in vacuo to afford $\left(R^{*}\right)$ - $N$-(4-chloro-3-((3-cyclopropylpyrrolidin1-yl)sulfonyl)phenyl)-2-(5-methyl-4,5,6,7-tetra $\quad$ hydro- $1 H$-[1,2,3]triazolo[4,5-c]pyridin-1yl)acetamide $(\boldsymbol{S}) \mathbf{- 5 5}(15 \mathrm{mg}, 0.031 \mathrm{mmol})$ as a white solid. Data consistent with racemate ((rac)3.127); Chiral LC: $4.6 \mathrm{~mm}$ x $250 \mathrm{~mm}$ Chiralpak IG column, $80 \%(\mathrm{EtOH}+2 \%$ isopropylamine $) /$ heptane, $(\boldsymbol{R})-\mathbf{5 5}: \mathrm{t}_{\mathrm{R}}=17.354 \mathrm{~min} ;$ er $>99: 1 ;(\boldsymbol{S})-\mathbf{5 5}: \mathrm{t}_{\mathrm{R}}=23.739 \mathrm{~min}$; er $>99: 1$.

\section{ATAD2 Synthetic Ligand Competition TR-FRET Binding Assay}

Compounds were titrated from $10 \mathrm{mM}$ in $100 \%$ DMSO, and $100 \mathrm{~nL}$ was transferred to a low-volume black 384-well microtiter plate using a Labcyte Echo 555. A Thermo Scientific Multidrop Micro was used to dispense $5 \mu \mathrm{L}$ of 5 nM FLAG-6His-Tev-ATAD2(981-1121) in 50 $\mathrm{mM}$ Hepes, $150 \mathrm{mM} \mathrm{NaCl}, 5 \%$ Glycerol, $1 \mathrm{mM}$ CHAPS, and $1 \mathrm{mM}$ DTT, $\mathrm{pH}$ 7.4, in the presence of $100 \mathrm{nM}$ Alexa Fluor 488-labeled ligand. After equilibrating for $30 \mathrm{~min}$ in the dark at $\mathrm{rt}$, the ATAD2 protein-fluorescent ligand interaction was detected using TR-FRET following a $5 \mu \mathrm{L}$ addition of 1.5 nM Lanthascreen Elite Tb-anti His antibody (Invitrogen, PV5863) in assay buffer. Time-resolved fluorescence (TRF) was then detected on a TRF laser equipped PerkinElmer Envision multimode plate reader $($ excitation $=337 \mathrm{~nm}$; emission $1=520 \mathrm{~nm}$; emission $2=495$ 
$\mathrm{nm}$; dual wavelength bias dichroic $=400,505 \mathrm{~nm}$ ). TR-FRET ratio was calculated using the following equation: ratio $=(($ acceptor fluorescence at $520 \mathrm{~nm}) /($ donor fluorescence at $495 \mathrm{~nm})) \times$ 1000. TR FRET ratio data was normalized to a mean of 16 replicates per microtiter plate of both $10 \mu \mathrm{M}$ GSK3190320 and 100\% DMSO controls. IC 50 values were determined for each of the compounds tested by fitting the fluorescence ratio data to a four parameter curve fit of the following form was then applied.

$$
y=\frac{a-d}{1+(x / c)^{b}}+d
$$

Where ' $a$ ' is the minimum, ' $b$ ' is the Hill slope, ' $c$ ' is the pIC50 and' $\mathrm{d}$ ' is the maximum.

\section{CECR2 Synthetic Ligand Competition TR-FRET Binding Assay}

Compounds were titrated from $10 \mathrm{mM}$ in $100 \% \mathrm{DMSO}$, and $100 \mathrm{~nL}$ was transferred to a low-volume black 384-well microtiter plate using a Labcyte Echo 555. A Thermo Scientific Multidrop Micro was used to dispense $5 \mu \mathrm{L}$ of $6 \mathrm{H}-$ FLAG-tev-CECR2 (424-543) in 50 mM Hepes, $150 \mathrm{mM} \mathrm{NaCl}, 5 \%$ Glycerol, $1 \mathrm{mM}$ CHAPS, and $1 \mathrm{mM}$ DTT, $\mathrm{pH} 7.4$, in the presence of $200 \mathrm{nM}$ Alexa Fluor 647-labeled ligand (GSK3103956A). After equilibrating for $15 \mathrm{~min}$ at rt, the CECR2 protein-fluorescent ligand interaction was detected using TR-FRET following a $5 \mu \mathrm{L}$ addition of 3 nM Eu-W1024-labeled Anti-6xHis antibody in assay buffer. Time-resolved fluorescence (TRF) was then detected on a TRF laser equipped PerkinElmer Envision multimode plate reader $($ excitation $=315 \mathrm{~nm}$; emission $1=665 \mathrm{~nm}$; emission $2=615 \mathrm{~nm})$. TR-FRET ratio was calculated using the following equation: ratio $=(($ acceptor fluorescence at $665 \mathrm{~nm}) /($ donor fluorescence at $615 \mathrm{~nm})) \times 1000$. TR FRET ratio data was normalized to a mean of 16 replicates per microtiter plate of both no protein and $100 \%$ DMSO controls. IC $_{50}$ values were determined for each of the compounds tested by fitting the fluorescence ratio data to a four parameter curve fit of the following form was then applied. 


$$
y=\frac{a-d}{1+(x / c)^{b}}+d
$$

Where ' $a$ ' is the minimum, ' $b$ ' is the Hill slope, ' $c$ ' is the pIC50 and' $\mathrm{d}$ ' is the maximum.

\section{BRD4 Mutant TR-FRET ASSAY ${ }^{51}$}

The binding of the compounds to BRD4 was assessed using a mutated protein to detect differential binding to Binding Domain 1 (BD1) on the bromodomain containing protein. The single residue mutation in the Binding Domain 2 (BD2) acetyl lysine binding pocket (Y390A) greatly lowers the affinity of the fluoroligand for the mutated BD2 domain ( $>1000$ fold selective for the non-mutated domain). Therefore in the final assay conditions, binding of the fluoroligand to the mutated BD2 domain cannot be detected and subsequently the assay is suitable to determine the binding of compounds to the single non-mutated BD1 bromodomain.

\section{Protocol for BRD4 BD1 ligand FRET assay}

All assay components were dissolved in buffer composition of $50 \mathrm{mM}$ HEPES pH 7.4, 50 $\mathrm{mM} \mathrm{NaCl}, 5 \%$ Glycerol, $1 \mathrm{mM}$ DTT and $1 \mathrm{mM}$ CHAPS. The final concentration of BRD4 protein (1-477, Y390A) was at $10 \mathrm{nM}$ and the Alexa Fluor647 ligand was at $K d$ ( 50 nM for BRD4). These components were premixed and $5 \mu \mathrm{L}$ of this reaction mixture was added to all wells containing $50 \mathrm{~nL}$ of various concentrations of test compound or DMSO vehicle (0.5\% DMSO final) in Greiner 384 well black low volume microtitre plates and incubated in dark for 30 min at rt. Detection reagents were prepared in assay buffer by diluting Eu-W1024 Anti- 6xHis Antibody (AD0111 PerkinElmer) to $1.5 \mathrm{nM} \mathrm{FAC.} 5 \mu \mathrm{l}$ of this solution was then added to all wells. The plates were read on the Envision reader and the donor and acceptor counts were determined. From this, the ratio of acceptor/donor was calculated $(\lambda \mathrm{ex}=337 \mathrm{~nm}, \lambda \mathrm{em}$ donor $=615 \mathrm{~nm}$, em acceptor $=$ $665 \mathrm{~nm}$ ) and used for data analysis. All data was normalized to the robust mean of 16 high and 16 low control wells on each plate. A four parameter curve fit of the following form was then applied. 


$$
y=\frac{a-d}{1+(x / c)^{b}}+d
$$

Where ' $a$ ' is the minimum, ' $b$ ' is the Hill slope, ' $c$ ' is the pIC50 and' $\mathrm{d}$ ' is the maximum.

\section{Physicochemical Properties}

Permeability across a lipid membrane, chromatographic $\log \mathrm{D}$ at $\mathrm{pH} 7.4$, and solubility by precipitation into saline were measured using published protocols. ${ }^{28,52-54}$

\section{ASSOCIATED CONTENT}

\section{Supporting Information.}

BRD2,3 and T TR-FRET data and DiscoverX BROMOscan® Bromodomain Profiling of key compounds, a comparison of CLND and CAD solubility measurements, correlation between TRFRET and DiscoverX BROMOscan TAF1(2) data, X-ray crystallographic data, chemistry experimental procedures and selected NMR Spectra (PDF)

Molecular formula strings (CSV)

PDB IDs

Crystallography structures are deposited as 3NXB, 4QSP, 6S55 and TBC. Authors will release the unpublished PDB ID, atomic coordinates and experimental data upon article publication

\section{AUTHOR INFORMATION}

\section{Corresponding Author(s)}

\section{S.J.A: E-mail: stephen.j.atkinson@gsk.com}

\section{Present Addresses}

${ }^{\sharp}$ Robert J. Sheppard Current Address: Medicinal Chemistry, Research and Early Development, Cardiovascular, Renal, and Metabolism, BioPharmaceuticals R\&D, AstraZeneca, Gothenburg 431 50, Sweden. 


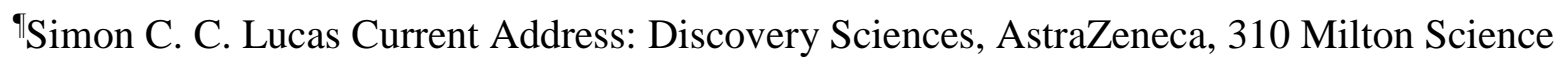
Park, Cambridge, CB4 0WG, UK.

\section{Author Contributions}

The manuscript was written through contributions of all authors. All authors have given approval to the final version of the manuscript.

\section{Funding Sources}

The authors declare the following competing financial interest(s): All authors except S.C.C.L. and N.C.O.T. were GlaxoSmithKline full-time employees when this study was performed. We thank the EPSRC for funding via Prosperity Partnership EP/S035990/1.

\section{ACKNOWLEDGMENTS}

S.C.C.L. is grateful to GlaxoSmithKline R\&D and the EPSRC via Prosperity Partnership EP/S035990/1 for Ph.D. studentship funding. Chiral analysis and separation were carried out by Eric Hortense, Richard Briers and Steve Jackson. We also wish to thank Sean Lynn and Stephen Richards for assistance with NMR spectra and Emily Lowndes for crystallisation support.

\section{ABBREVIATIONS}

AMP, artificial membrane permeability; ATAD2, ATPase Family AAA Domain Containing 2; BD1, first (N-terminal) bromodomain; BD2, second (C-terminal) bromodomain; BET, bromodomain and extra-terminal domain; BRD2/3/4, bromodomain-containing protein 2/3/4; BTPF, bromodomain PHD finger transcription factor; CAD, charged aerosol detection; CECR2, Cats Eye Chromosome Region, Candidate 2; ChromLogD, Chromatographic LogD; CLND, 
charged luminescence nitrogen detection; DMSO, dimethyl sulfoxide; HRMS, high-resolution mass spectra; KAc, acetylated lysine; LE, Ligand Efficiency; LLEat, Lipophilic Ligand Efficiency, Astex; MDAP, mass directed automatic purification; RVF. Arginine-valine-phenylalanine; Sel., selectivity; TR-FRET, time resolved-fluorescence resonance energy transfer, WPF, tryptophanproline-phenylalanine.

\section{REFERENCES}

1. Jain, A. K.; Barton, M. C., Bromodomain Histone Readers and Cancer. J. Mol. Biol. 2017, 429 (13), 2003-2010.

2. Filippakopoulos, P.; Knapp, S., Targeting bromodomains: epigenetic readers of lysine acetylation. Nat. Rev. Drug Discov. 2014, 13, 337.

3. Smith, S. G.; Zhou, M.-M., The Bromodomain: A New Target in Emerging Epigenetic Medicine. ACS Chem. Biol. 2016, 11 (3), 598-608.

4. Lovén, J.; Hoke, H. A.; Lin, C. Y.; Lau, A.; Orlando, D. A.; Vakoc, C. R.; Bradner, J. E.; Lee, T. I.; Young, R. A., Selective Inhibition of Tumor Oncogenes by Disruption of Super-Enhancers. Cell 2013, 153 (2), 320-334.

5. Huang, B.; Yang, X.-D.; Zhou, M.-M.; Ozato, K.; Chen, L.-F., Brd4 Coactivates Transcriptional Activation of NF-KB via Specific Binding to Acetylated RelA. Mol. Cell. Biol. 2009, 29 (5), 1375-1387.

6. Theodoulou, N. H.; Tomkinson, N. C. O.; Prinjha, R. K.; Humphreys, P. G., Clinical progress and pharmacology of small molecule bromodomain inhibitors. Curr. Opin. Chem. Biol. 2016, 33, 58-66.

7. Zhang, G.; Sanchez, R.; Zhou, M., Scaling the Druggability Landscape of Human Bromodomains, a New Class of Drug Targets. J. Med. Chem. 2012, 55 (17), 7342-7345.

8. Moustakim, M.; Clark, P. G. K.; Hay, D. A.; Dixon, D. J.; Brennan, P. E., Chemical probes and inhibitors of bromodomains outside the BET family. MedChemComm 2016, 7 (12), 2246-2264.

9. Theodoulou, N. H.; Tomkinson, N. C. O.; Prinjha, R. K.; Humphreys, P. G., Progress in the Development of non-BET Bromodomain Chemical Probes. ChemMedChem 2016, 11 (5), 477-487.

10. Sweis, R. F., Target (In)Validation: A Critical, Sometimes Unheralded, Role of Modern Medicinal Chemistry. ACS Med. Chem. Lett. 2015, 6 (6), 618-621.

11. Conway, S. J., Bromodomains: Are Readers Right for Epigenetic Therapy? ACS Med. Chem. Lett. 2012, 3 (9), 691-694.

12. Romero, F. A.; Taylor, A. M.; Crawford, T. D.; Tsui, V.; Côté, A.; Magnuson, S., Disrupting AcetylLysine Recognition: Progress in the Development of Bromodomain Inhibitors. J. Med. Chem. 2016, 59

(4), 1271-1298.

13. Clegg, M. A.; Tomkinson, N. C. O.; Prinjha, R. K.; Humphreys, P. G., Advancements in the Development of non-BET Bromodomain Chemical Probes. ChemMedChem 2019, 14 (4), 362-385.

14. Bunnage, M. E.; Chekler, E. L. P.; Jones, L. H., Target validation using chemical probes. Nat. Chem. Biol. 2013, 9 (4), 195-199.

15. Frye, S. V., The art of the chemical probe. Nat. Chem. Biol. 2010, 6, 159.

16. Clegg, M. A.; Tomkinson, N. C.; Prinjha, R. K.; Humphreys, P. G., Small molecules and their role in effective preclinical target validation. Future Med. Chem. 2017, 9 (14), 1579-1582. 
17. Zou, J. X.; Revenko, A. S.; Li, L. B.; Gemo, A. T.; Chem, H.-W., ANCCA, an estrogen-regulated AAA+ ATPase coactivator for ERa, is required for coregulator occupancy and chromatin modification. Proc. Natl. Acad. Sci. USA 2007, 104 (46), 18067-18072.

18. Caron, C.; Lestrat, C.; Marsal, S.; Escoffier, E.; Curtet, S.; Virolle, V.; Barbry, P.; Debernardi, A.; Brambilla, C.; Brambilla, E.; Rousseaux, S.; Khochbin, S., Functional characterization of ATAD2 as a new cancer/testis factor and a predictor of poor prognosis in breast and lung cancers. Oncogene 2010, 29 (37), 5171-5181.

19. Boussouar, F.; Jamshidikia, M.; Morozumi, Y.; Rousseaux, S.; Khochbin, S., Malignant genome reprogramming by ATAD2. Biochim. Biophys. Acta 2013, 1829 (10), 1010-1014.

20. Banting, G. S.; Barak, O.; Ames, T. M.; Burnham, A. C.; Kardel, M. D.; Cooch, N. S.; Davidson, C. E.; Godbout, R.; McDermid, H. E.; Shiekhattar, R., CECR2, a protein involved in neurulation, forms a novel chromatin remodeling complex with SNF2L. Hum. Mol. Genet. 2005, 14 (4), 513-524.

21. Toyoshima, M.; Howie, H. L.; Imakura, M.; Walsh, R. M.; Annis, J. E.; Chang, A. N.; Frazier, J.; Chau, B. N.; Loboda, A.; Linsley, P. S.; Cleary, M. A.; Park, J. R.; Grandori, C., Functional genomics identifies therapeutic targets for MYC-driven cancer. Proc. Natl. Acad. Sci. USA 2012, 109 (24), 95459550.

22. Lee, S.-K.; Park, E.-J.; Lee, H.-S.; Lee, Y. S.; Kwon, J., Genome-wide screen of human bromodomain-containing proteins identifies Cecr2 as a novel DNA damage response protein. Mol. Cells 2012, 34 (1), 85-91.

23. Vidler, L. R.; Brown, N.; Knapp, S.; Hoelder, S., Druggability Analysis and Structural Classification of Bromodomain Acetyl-lysine Binding Sites. J. Med. Chem. 2012, 55 (17), 7346-7359.

24. Hussain, M.; Zhou, Y.; Song, Y.; Hameed, H. M. A.; Jiang, H.; Tu, Y.; Zhang, J., ATAD2 in cancer: a pharmacologically challenging but tractable target. Expert Opin. Ther. Targets 2018, 22 (1), 85-96.

25. Chaikuad, A.; Petros, A. M.; Fedorov, O.; Xu, J.; Knapp, S., Structure-based approaches towards identification of fragments for the low-druggability ATAD2 bromodomain. MedChemComm 2014, 5 (12), 1843-1848.

26. Demont, E. H.; Chung, C.-w.; Furze, R. C.; Grandi, P.; Michon, A.-M.; Wellaway, C.; Barrett, N.; Bridges, A. M.; Craggs, P. D.; Diallo, H.; Dixon, D. P.; Douault, C.; Emmons, A. J.; Jones, E. J.; Karamshi, B. V.; Locke, K.; Mitchell, D. J.; Mouzon, B. H.; Prinjha, R. K.; Roberts, A. D.; Sheppard, R. J.; Watson, R. J.; Bamborough, P., Fragment-Based Discovery of Low-Micromolar ATAD2 Bromodomain Inhibitors. J. Med. Chem. 2015, 58 (14), 5649-5673.

27. Bamborough, P.; Chung, C.-w.; Furze, R. C.; Grandi, P.; Michon, A.-M.; Sheppard, R., J.; Barnett, H.; Diallo, H.; Dixon, D. P.; Douault, C.; Jones, E. J.; Karamshi, B.; Mitchell, D. J.; Prinjha, R. K.; Rau, C.; Watson, R. J.; Werner, T.; Demont, E. H., Structure-Based Optimization of Naphthyridones into Potent ATAD2 Bromodomain Inhibitors. J. Med. Chem. 2015, 58 (15), 6151-6178.

28. Bamborough, P.; Chung, C.-w.; Demont, E. H.; Furze, R. C.; Bannister, A. J.; Che, K. H.; Diallo, H.; Douault, C.; Grandi, P.; Kouzarides, T.; Michon, A.-M.; Mitchell, D. J.; Prinjha, R. K.; Rau, C.; Robson, S.; Sheppard, R. J.; Upton, R.; Watson, R. J., A Chemical Probe for the ATAD2 Bromodomain. Angew. Chem. Int. Ed. 2016, 55 (38), 11382-11386.

29. Fernández-Montalván, A. E.; Berger, M.; Kuropka, B.; Koo, S. J.; Badock, V.; Weiske, J.; Puetter, V.; Holton, S. J.; Stöckigt, D.; ter Laak, A.; Centrella, P. A.; Clark, M. A.; Dumelin, C. E.; Sigel, E. A.; Soutter, H. H.; Troast, D. M.; Zhang, Y.; Cuozzo, J. W.; Keefe, A. D.; Roche, D.; Rodeschini, V.; Chaikuad, A.; DíazSáez, L.; Bennett, J. M.; Fedorov, O.; Huber, K. V. M.; Hübner, J.; Weinmann, H.; Hartung, I. V.; Gorjánácz, M., Isoform-Selective ATAD2 Chemical Probe with Novel Chemical Structure and Unusual Mode of Action. ACS Chem. Biol. 2017, 12 (11), 2730-2736.

30. https://www.thesgc.org/chemical-probes/NVS-1. (accessed 22/03/2019).

31. https://www.thesgc.org/chemical-probes/TP-238. (accessed 22/03/2019). 
32. Crawford, T. D.; Audia, J. E.; Bellon, S.; Burdick, D. J.; Bommi-Reddy, A.; Côté, A.; Cummings, R. T.; Duplessis, M.; Flynn, E. M.; Hewitt, M.; Huang, H.-R.; Jayaram, H.; Jiang, Y.; Joshi, S.; Kiefer, J. R.; Murray, J.; Nasveschuk, C. G.; Neiss, A.; Pardo, E.; Romero, F. A.; Sandy, P.; Sims, R. J.; Tang, Y.; Taylor, A. M.; Tsui, V.; Wang, J.; Wang, S.; Wang, Y.; Xu, Z.; Zawadzke, L.; Zhu, X.; Albrecht, B. K.; Magnuson, S. R.; Cochran, A. G., GNE-886: A Potent and Selective Inhibitor of the Cat Eye Syndrome Chromosome Region Candidate 2 Bromodomain (CECR2). ACS Med. Chem. Lett. 2017, 8 (7), 737-741.

33. Bamborough, P.; Chung, C.-W.; Demont, E. H.; Bridges, A. M.; Craggs, P. D.; Dixon, D. P.; Francis, P.; Furze, R. C.; Grandi, P.; Jones, E. J.; Karamshi, B.; Locke, K.; Lucas, S. C. C.; Michon, A.-M.; Mitchell, D. J.; Pogány, P.; Prinjha, R. K.; Rau, C.; Roa, A. M.; Roberts, A. D.; Sheppard, R. J.; Watson, R. J., A Qualified Success: Discovery of a New Series of ATAD2 Bromodomain Inhibitors with a Novel Binding Mode Using High-Throughput Screening and Hit Qualification. J. Med. Chem. 2019, 62 (16), 7506-7525.

34. Hill, A. P.; Young, R. J., Getting physical in drug discovery: a contemporary perspective on solubility and hydrophobicity. Drug Discov. Today 2010, 15 (15), 648-655.

35. Young, R. J.; Green, D. V. S.; Luscombe, C. N.; Hill, A. P., Getting physical in drug discovery II: the impact of chromatographic hydrophobicity measurements and aromaticity. Drug Discov. Today 2011, 16 (17), 822-830.

36. Bayliss, M. K.; Butler, J.; Feldman, P. L.; Green, D. V. S.; Leeson, P. D.; Palovich, M. R.; Taylor, A. J., Quality guidelines for oral drug candidates: dose, solubility and lipophilicity. Drug Discov. Today 2016, 21 (10), 1719-1727.

37. Lin, B.; Pease, J. H., A high throughput solubility assay for drug discovery using microscale shakeflask and rapid UHPLC-UV-CLND quantification. J. Pharm. Biomed. Anal. 2016, 122, 126-140.

38. Kestranek, A.; Chervenak, A.; Longenberger, J.; Placko, S., Chemiluminescent Nitrogen Detection (CLND) to Measure Kinetic Aqueous Solubility. In Curr. Protoc. Chem. Biol., John Wiley \& Sons, Inc.: 2009. 39. Kansy, M.; Senner, F.; Gubernator, K., Physicochemical High Throughput Screening: Parallel Artificial Membrane Permeation Assay in the Description of Passive Absorption Processes. J. Med. Chem. 1998, 41 (7), 1007-1010.

40. Robinson, M. W.; Hill, A. P.; Readshaw, S. A.; Hollerton, J. C.; Upton, R. J.; Lynn, S. M.; Besley, S. C.; Boughtflower, B. J., Use of Calculated Physicochemical Properties to Enhance Quantitative Response When Using Charged Aerosol Detection. Anal. Chem. 2017, 89 (3), 1772-1777.

41. Aldeghi, M.; Ross, G. A.; Bodkin, M. J.; Essex, J. W.; Knapp, S.; Biggin, P. C., Large-scale analysis of water stability in bromodomain binding pockets with grand canonical Monte Carlo. Communications Chemistry 2018, 1 (1), 19.

42. Machleidt, T.; Woodroofe, C. C.; Schwinn, M. K.; Méndez, J.; Robers, M. B.; Zimmerman, K.; Otto, P.; Daniels, D. L.; Kirkland, T. A.; Wood, K. V., NanoBRET-A Novel BRET Platform for the Analysis of Protein-Protein Interactions. ACS Chem. Biol. 2015, 10 (8), 1797-1804.

43. Filippakopoulos, P.; Picaud, S.; Mangos, M.; Keates, T.; Lambert, J.-P.; Barsyte-Lovejoy, D.; Felletar, I.; Volkmer, R.; Müller, S.; Pawson, T.; Gingras, A.-C.; Arrowsmith, Cheryl H.; Knapp, S., Histone Recognition and Large-Scale Structural Analysis of the Human Bromodomain Family. Cell 2012, 149 (1), 214-231.

44. Zhang, G.; Smith, S. G.; Zhou, M., Discovery of Chemical Inhibitors of Human Bromodomains. Chem. Rev. 2015, 115 (21), 11625-11668.

45. Mispelaere-Canivet, C.; Spindler, J.-F.; Perrio, S.; Beslin, P., Pd2(dba)3/Xantphos-catalyzed crosscoupling of thiols and aryl bromides/triflates. Tetrahedron 2005, 61 (22), 5253-5259.

46. Pu, Y.-M.; Christesen, A.; Ku, Y.-Y., A simple and highly effective oxidative chlorination protocol for the preparation of arenesulfonyl chlorides. Tetrahedron Lett. 2010, 51 (2), 418-421.

47. Lee, B.-Y.; Park, S. R.; Jeon, H. B.; Kim, K. S., A new solvent system for efficient synthesis of 1,2,3triazoles. Tetrahedron Lett. 2006, 47 (29), 5105-5109. 
48. Boren, B. C.; Narayan, S.; Rasmussen, L. K.; Zhang, L.; Zhao, H.; Lin, Z.; Jia, G.; Fokin, V. V., Ruthenium-Catalyzed Azide-Alkyne Cycloaddition: Scope and Mechanism. J. Am. Chem. Soc. 2008, 130 (28), 8923-8930.

49. Alekseev, R. S.; Kurkin, A. V.; Yurovskaya, M. A., Use of the Graebe-Ullmann reaction in the synthesis of 8-methyl- $\gamma$-carboline and isomeric aromatic aza- $\nu$-carbolines. Chemistry of Heterocyclic Compounds 2012, 48 (8), 1235-1250.

50. Yutilov, Y. M.; Smolyar, N. N.; Abramyants, M. G.; Izotova, N. P., Synthesis of Ticlopidine Analogs Based on Spinaceamine and 2-Azaspinaceamine. Pharm. Chem. J. 2003, 37 (5), 243-245.

51. Chung, C.-w.; Coste, H.; White, J. H.; Mirguet, O.; Wilde, J.; Gosmini, R. L.; Delves, C.; Magny, S. M.; Woodward, R.; Hughes, S. A.; Boursier, E. V.; Flynn, H.; Bouillot, A. M.; Bamborough, P.; Brusq, J.-M. G.; Gellibert, F. J.; Jones, E. J.; Riou, A. M.; Homes, P.; Martin, S. L.; Uings, I. J.; Toum, J.; Clément, C. A.; Boullay, A.-B.; Grimley, R. L.; Blandel, F. M.; Prinjha, R. K.; Lee, K.; Kirilovsky, J.; Nicodeme, E., Discovery and Characterization of Small Molecule Inhibitors of the BET Family Bromodomains. J. Med. Chem. 2011, 54 (11), 3827-3838.

52. Camurri, G.; Zaramella, A., High-Throughput Liquid Chromatography/Mass Spectrometry Method for the Determination of the Chromatographic Hydrophobicity Index. Anal. Chem. 2001, 73 (15), 3716-3722.

53. Valko, K.; Nunhuck, S.; Bevan, C.; Abraham, M. H.; Reynolds, D. P., Fast gradient HPLC method to determine compounds binding to human serum albumin. Relationships with octanol/water and immobilized artificial membrane lipophilicity. J. Pharm. Sci. 2003, 92 (11), 2236-2248.

54. Bamborough, P.; Chung, C.-w.; Furze, R. C.; Grandi, P.; Michon, A.-M.; Sheppard, R. J.; Barnett, H.; Diallo, H.; Dixon, D. P.; Douault, C.; Jones, E. J.; Karamshi, B.; Mitchell, D. J.; Prinjha, R. K.; Rau, C.; Watson, R. J.; Werner, T.; Demont, E. H., Structure-Based Optimization of Naphthyridones into Potent ATAD2 Bromodomain Inhibitors. J. Med. Chem. 2015, 58 (15), 6151-6178. 